PRIMARY ORAL RECONSTRUCTIONS WITH MICROVASCULAR FLAPS IN PATIENTS WITH ORAL CANCER IN ADVANCED STAGES, IMPACT ON SURVIVAL AND QUALITY OF LIFE OF PATIENTS

Summary of the Doctoral Thesis for obtaining the degree of a Doctor of Medicine Speciality - Plastic Surgery 


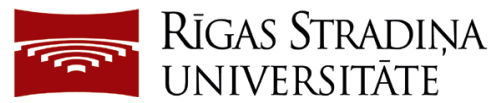

Kalvis Pastars

\section{PRIMARY ORAL RECONSTRUCTIONS WITH MICROVASCULAR FLAPS IN PATIENTS WITH ORAL CANCER IN ADVANCED STAGES, IMPACT ON SURVIVAL AND QUALITY OF LIFE OF PATIENTS}

Summary of the Doctoral Thesis for obtaining the degree of a Doctor of Medicine

Speciality - Plastic Surgery

Riga, 2019 
The Doctoral Thesis was developed in Latvian Oncolgy Centre of Riga Eastern University Hospital in collaboration with Microsurgery Centre of Latvia.

Scientific supervisor:

Dr. habil. med., Professor Andrejs Skagers,

Department of Oral and Maxillofacial Surgery of

Rīga Stradiņš University, Latvia

Official reviewers:

Dr. med., Associate Professor Jānis Eglītis,

Onkology Department of University of Latvia

Dr. habil. med., Professor Ričardas Kubilius,

Department of Oral and Maxillofacila Surgery

of Lithuanian University of Health Sciences

Dr. med., Professor Ingrīda Čēma,

Department of Oral Medicine of Rīga Stradiņš University, Latvia

Defence of the Doctoral Thesis will take place at the public session of the Doctoral Council of Medicine on 10 July 2019 at 14.00 in Hippocrates Lecture Theatre, 16 Dzirciema Street, Rīga Stradiņš University.

The Doctoral Thesis is available in the RSU library and at RSU webpage: www.rsu.lv.

Secretary of the Doctoral Council:

Dr. med. Assistant Professor Gunta Sumeraga 


\section{TABLE OF CONTENTS}

INTRODUCTION

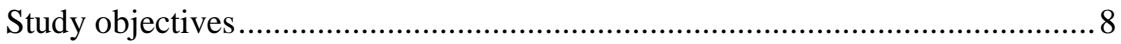

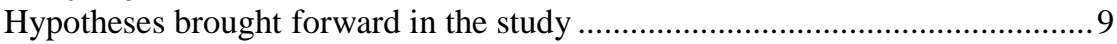

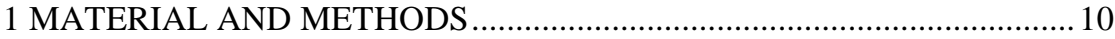

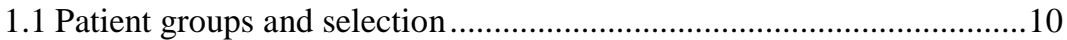

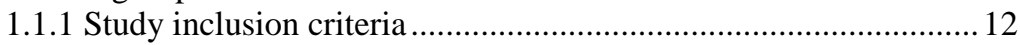

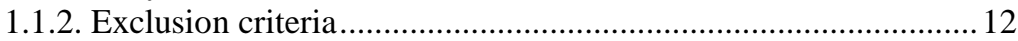

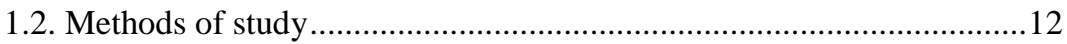

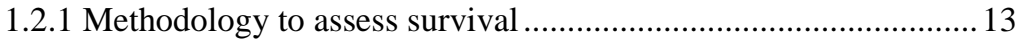

1.2.2 Quality of life assessment methodology ..................................... 14

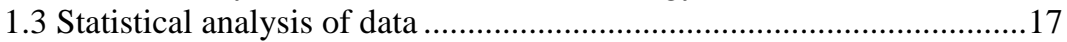

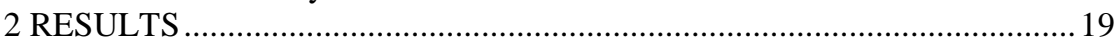

2.1 Clinical and cancer pathomorphological characterization

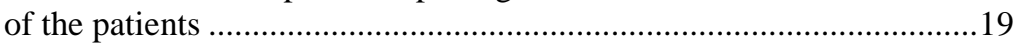

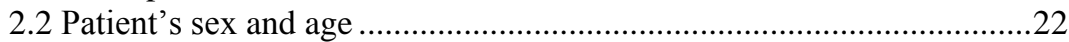

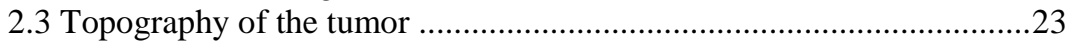

2.4 Classification by TNM system..........................................................24

2.5 The relationship of tumor localization with a frequency of the cervical

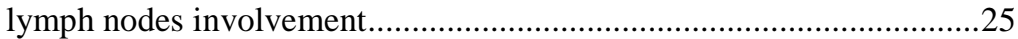

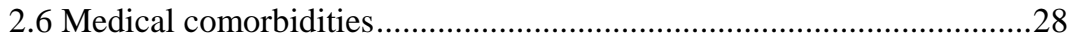

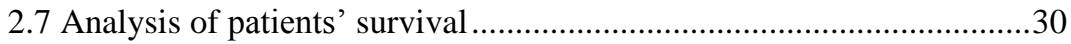

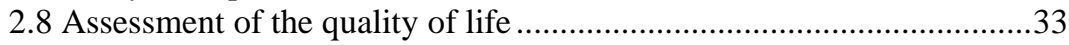

2.9 Application of methods of microvascular reconstruction.........................36

2.10 Analysis of the patients' hospital stay in the study group ....................37

2.11 Analysis of post-operative complications in the study group...............38

2.12 Effect of reconstruction type on the frequency of

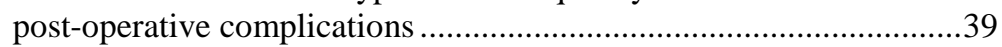

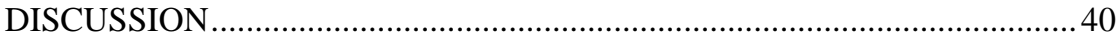

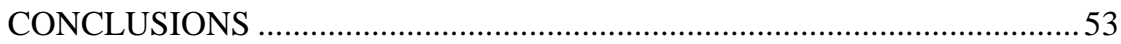

PUBLICATIONS AND REPORTS ON THE STUDY THEME …................54

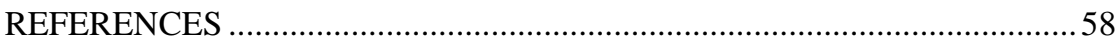

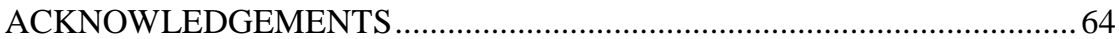




\section{INTRODUCTION}

Head and neck cancer is a common epithelial tumor localized at oral cavity, paranasal sinuses, nasopharynx, oropharynx, hypopharynx and larynx. It has been estimated each year 644000 new cases of head and neck cancer worldwide, from which two thirds in developing countries. An average age of patient with head and neck cancer is 60 years. Men have tree times higher incidence than women (Jemal 2011).

The main focus of our study is patients with advanced stage (stage III and stage IV) cancer, which treatment is more complex and treatment outcome performing convencional treatment methods remains unclear. Surgical treatment of oral cancer in advanced stages results in wide oral tissue defects, which reconstruction is complicated due to complex structure of oral cavity. Oral reconstruction with microvascular free flap provides promising functional and esthetical results for patients with oral cancer.

The factors that influence the choise of cancer treatment are related to cancer characteristics. Cancer primary size, location, proximity to bone, cervical node involvement and histology are factors influencing treatment modality options. TNM system classifies cancers by the size and extent of the primary tumor $(\mathrm{T})$, involvement of regional lymph node $(\mathrm{N})$ and presence or absence of distant metastasis $(\mathrm{M})$.

Advanced stage of oral cancer is characterized by size of tumor (T3 and T4) and/or cervical lymph node involvement (N1, N2, N3). T2 (tumor more than $2 \mathrm{~cm}$ but less than $4 \mathrm{~cm}$ in greatest dimension) and N0 (no cervical lymph node involvement) have been considered a borderline between non-advanced and advanced disease. Tobacco and alcohol consumption reduce ability to regenerate oral epithelium therefore they are considered as the main etiological factors for oral cancer. Also, insufficient dental care has been reported as a possible 
etiological factor. A study showed that patients younger than 64 years with oral cancer had toothless jaw and random dentist visits (Rubright, Hoffman et al. 1996).

Incidence of oncological illneses has been incresed during last 10 years in Latvia. Data of the Centre for Disease Prevention and Control (CDPC) of Latvia shows that 477,5 new cancer cases to 100000 population have been estimated in 2006 , but 567,5 new cancer cases to 100000 population were estimated in 2016. It is a $16 \%$ increase in 10 years.

According to information of CDPC from 12.06.2017. updated Patient register 200 patients were diagnosed with lips, mouth, hypopharynx tumors (C00-C10, according to the SKK-10 classifier), which are 10.2 patients to 100 000 population in 2016. In 2009 they were 6.92 patients per 100000 inhabitants. It should be noted that in 2016132 from 200 patients who have been diagnosed with a malignant tumor were diagnosed at a late stage (in stage III -45 patients, but in stage IV - 87 patients). For 21 patients the oral cancer was diagnosed without stage clarification. In 2009, in 86 from 118 patients, oral cancer was diagnosed in an advanced stage (stage III for 21 patients and for 65 patients stage IV was found). When analyzing age groups, in 2009 the highest incidence of oral cancer in women was 70-74 years of age, but in 2016 the highest incidence had the age group from 55 to 59 years. For men, the highest incidence, both in 2009 and 2016, were in the age group of 60-64 and only slightly lower incidence was found in 50-54 years of age. At the end of 2016, with diagnoses C00-C10 in Latvian records of the oncological patients register there were 873 patients to 100000 inhabitants, from them 472 patients survived for more than five years after diagnosed cancer.

Worldwide, in the recent years, an average survival of the patients with oral cancer has been significantly improved. If during the 60-ies the 5-year survival rate was 48\%, then in 2000 it reached 63\% (Montero and Patel 2015). 
Although the total 5-year survival rates for oral cancer have improved over the last 30-40 years, this is mainly due to improved diagnostics and treatment of cancer diagnosed at the early stages. Unfortunately, for patients with oral cancer in advanced stages survival rates are not so promising.

In the world, the 5-year survival data for patients with oral cancer in late stages are different, which would be explained by the availability of health care, the level of public education and welfare in a given region. Schneider et al. in his study, analysing 5-year of survival in Brazil-treated patients showed that in patients with advanced-stage cancer, the 5-year survival rate was 30.8\% (Schneider, Flores et al. 2014). However, the performed study at the University of Washington was shown that 5-year survival of the treated patients with oral cancer reached 57\% (Sessions, Spector et al. 2002). In summary articles the fiveyear survival rate for patients with oral cancer was 50\% (Kumar, Nanavati et al. 2016), but this figure was achieved in only a few publications. When studying further the oral tumor treatment results of advanced stages, it can be seen that the picture is not so optimistic, and the results may vary dramatically.

The different survival of treated patients with oral cancer is associated with the diversity of available treatment methods and the possibilities to combine them in different countries. Pablo H. Montero and Snehal G. Patel compiled the survival rates available in the literature in different countries of the world, see Table 1 (Montero and Patel 2015).

Table 1

\section{Summarized data of the 5-year survival rate for the mouth cancer treated patients in the world's countries}

\begin{tabular}{|l|c|c|c|c|c|c|c|}
\hline Country & Year & $\begin{array}{c}\text { Qantity of } \\
\text { patients }\end{array}$ & $\begin{array}{c}\text { 5-year survival } \\
\text { from all patients } \\
(\%)\end{array}$ & $\begin{array}{c}\text { Stage } \\
\text { I } \\
(\%)\end{array}$ & $\begin{array}{c}\text { Stage } \\
\text { II } \\
(\%)\end{array}$ & $\begin{array}{c}\text { Stage } \\
\text { III } \\
(\%)\end{array}$ & $\begin{array}{c}\text { Stage } \\
\text { IV } \\
(\%)\end{array}$ \\
\hline USA & 1997. & 398 & 57 & - & - & - & - \\
\hline Taiwan & 1999. & 7032 & 36.1 & 72.0 & 38.9 & 26.7 & 11.8 \\
\hline USA & 2000. & 30803 & 43 & - & - & - & - \\
\hline
\end{tabular}


Table 1 continued

\begin{tabular}{|l|c|c|c|c|c|c|c|}
\hline Country & Year & $\begin{array}{c}\text { Qantity of } \\
\text { patients }\end{array}$ & $\begin{array}{c}\text { 5-year survival } \\
\text { from all patients } \\
(\%)\end{array}$ & $\begin{array}{c}\text { Stage } \\
\text { I } \\
(\%)\end{array}$ & $\begin{array}{c}\text { Stage } \\
\text { II } \\
(\%)\end{array}$ & $\begin{array}{c}\text { Stage } \\
\text { III } \\
(\%)\end{array}$ & $\begin{array}{c}\text { Stage } \\
\text { IV } \\
(\%)\end{array}$ \\
\hline Brazil & 2002. & 3642 & 43 & \multicolumn{2}{|c|}{74} & \multicolumn{2}{|c|}{33.0} \\
\hline India & 2000. & 15051 & 45.9 & \multicolumn{2}{|c|}{68.9} & 26.6 & 9.5 \\
\hline UK & 2008. & 541 & 56 & - & - & - & - \\
\hline USA & 2014. & 1816 & 62 & 78.5 & 68.4 & 64.5 & 34.5 \\
\hline
\end{tabular}

Unfortunately, also in the world $60 \%$ of cases of oral cancer are diagnosed and treatment started in stage III and IV with a 5-year survival of 10-40\% (Gorsky and Dayan 1995, Onizawa, Nishihara et al. 2003, Brouha, Tromp et al. 2005, Morelatto, Herrera et al. 2007, Huang and O'Sullivan 2013).

Currently, there is no exact 5-year survival statistics available for the oral cancer disease stages in Latvia.

In the non-treated patients with oral cancer in advanced stages, 5-year survival is found only at $12.6 \%$ of cases (Cheraghlou, Kuo et al. 2018).

Quality of life is a concept that includes both objective and subjective indicators, and a set of their mutual interactions, reflected in a definite degree of welfare, which depends on the resources and knowledge of the individual. The quality of life of people with disabilities means that the basic needs of the individual are met and that the individual has the potential to implement basic functions in society (education, work, family and social relations). In this study, a neglected, late-onset, radical surgical treatment possibilities of oncological patients were investigated, evaluating the medical results of microsurgical reconstruction. Conscious of the importance of quality of life in the life of oncology patients, we have also carried out subjective assessments of this aspect, taking into account the factors of personal and social life. 


\section{Aim of the study}

To demonstrate that in advanced stages (III-IV) of oral cancer, an excision of tumor and reconstruction of the defect with a microvascular flap as a one stage procedure, enables a radical treatment of patients with oral cancer at an advanced stage, prolongs patient survival and improves quality of life.

\section{Study objectives}

1. To compare 2-year survival in patients with advanced stage oral cancer undergoing single-stage surgery, with patients to whom a radiotherapy as a primary oral cancer treatment was applied.

2. To compare 5-year survival in patients for whom a one-stage, advanced stage oral cancer excision and oral reconstruction with microvascular flap was performed, with survival of patients treated with radiotherapy as primary treatment method.

3. To analyse the effect of various factors on survival in patients with the advanced stage oral cancer.

4. To conduct an analysis of the early post-operative period and the analysis of complications in a group of patients with soft tissue reconstruction and in patients with complex reconstruction of soft tissues and bone tissues.

5. To establish the quality of life and compare it for surgically treated patients before treatment, for 3 months after treatment and for 12 months after treatment. 


\section{Hypotheses brought forward in the study}

In the advanced stages of oral cancer, a single-stage excision of the tumor and reconstruction of the defect with a microvascular flap makes it possible to perform a radical treatment of the tumor.

The early complications of microvascular reconstructions depend on the stage of tumor, age of patients, adjacent diseases, and the method of reconstruction used.

Patient's quality of life parameters, performing reconstruction of the oral cavity with the microvascular flap are maintained or even improved compared to pre-treatment life-quality indicators.

The survival and quality of life of oral cancer patients depend on tumor location and the chosen method of oral cavity reconstruction. 


\section{MATERIAL AND METHODS}

\subsection{Patient groups and selection}

The study included 185 patients with clinically diagnosed and histologically confirmed oral cancer in the advanced stage. All patients were undergoing biopsia that verified tumor morphology. Patients were divided into two groups. The first group included 142 patients who were undergoing surgical treatment. For all patients was performed a surgery at Riga Eastern University Hospital, Latvian Oncology Centre from November 2008 to April 2016. For all 142 patients enrolled in the study, the tumor was histologically verified, status of lymph nodes evaluated, and remote metastases were excluded. Taking into account tumor localization and involvement of surrounding structures tumor excision was performed. For patients who had only soft tissue tumor without growth in the bone tissue only soft tissue resection was performed. In the cases, when the tumor was ingrown in lower jaw or upper jaw, the resection of the bone was also carried out (mandibulectomy, or maxillectomy). Cervical lymph nodes were evaluated using USG or, when indicated, CT or MRI had been performed. In patients who were suspected or diagnosed with specific lymphadenopathy, selective lymphoadenectomy of the affected or suspected lymph nodes was performed. To comply with main antiseptics and aseptics principles, in patients with oral cancer and specific lymphoadenopathy in the neck, first a selective lymphadenectomy was performed, and then the tumor excised. This reduced the risk of wound infection. After tumor excision, or in cases where the defect size was predicted, during tumor extirpation, flap elevation began. In patients who required a soft tissue reconstruction most often fasciocutaneous flaps were transplantated. The most commonly used flaps were radial forearm flap (RFF), 
lateral arm flap (LAF) or the anteriorlateral thigh flap (ALT). In patients who require a reconstruction of the lower jaw or upper jaw segment or a total reconstruction, an osteocutaneous flap or a chimera-type flap has been transplanted. Osteocutaneous flap includes a vascularized bone transplant and vascularized skin-fascia flap. The chimera-type flap may consist from a wide range of vascular pools, consisting of vascularized bone, muscle, fascia, tendon and skin. Flap design is adjusted in regard to which oral structures need to be reconstructed. In assessment of the final histology report, radiotherapy and, if necessary, chemotherapy was administered to the patients after the surgery. The indications were evaluated by the council of the radio- and chemotherapists. The application of chemotherapy was also coordinated with the National Health Service.

As a control group was used a group of patients who rejected surgical treatment, and as a primary treatment method radiotherapy was conducted, in individual cases where it was indicated adding chemotherapy. The control group included 43 patients. To verify tumor morphology all patients in the control group were subjected to biopsy. The patients in the control group received radiotherapy with or without additional chemotherapy. The treatment plan was approved in the oncologist consilium at the Latvian Oncology Centre of the Riga Eastern University Clinical University Hospital. In the consilium there was an otorinolaringologist, maxillofacial surgeon, radiotherapist, chemotherapist, and plastic surgeon. The use of chemotherapy was also coordinated with the National Health Service (NHS). The study was conducted from December 2, 2008 to February 18, 2018. 


\subsubsection{Study inclusion criteria}

The study included patients with:

- Clinical diagnosis and histological verification confirm the oral cancer at the advanced (III-IV) stage.

- Distant metastasis has not been found.

- Patient agrees to participate in the study.

\subsubsection{Exclusion criteria}

The study excluded patients with:

- Remote metastases diagnosed.

- The patient's general condition does not allow surgical treatment.

- The tumor is inoperable.

\subsection{Methods of study}

Study methods can be divided into two directions. The first direction of the study is to analyse pathomorphological characterisation of the tumor, tumor localization, its stage, treatment used, method of reconstruction, treatment outcome and patient survival. The patient selection criteria are explained in Figure 1.1. 


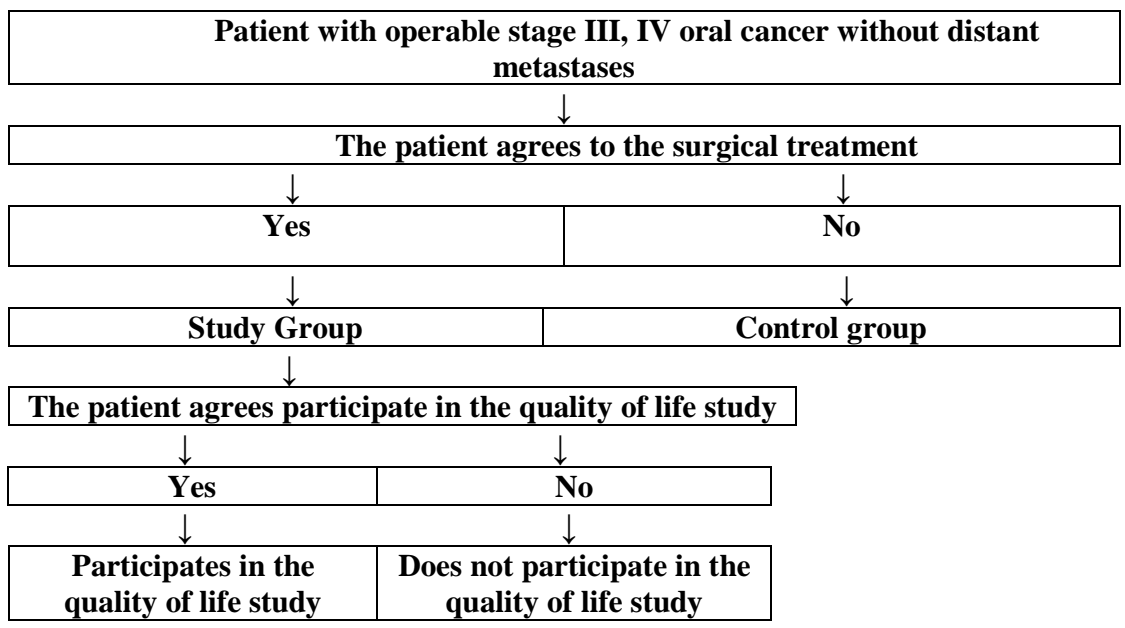

Figure 1.1 Patient selection criteria for study group, control group and quality of life study group

\subsubsection{Methodology to assess survival}

For patients included in the study group a tumor excision with or without neck dissection, and oral reconstruction with a microvascular flap was performed. Patients were observed from 5 days to 3103 days, with an average follow-up time of 860 days.

To evaluate the patient's general and local condition, function of the reconstructed part, as well as aesthetic result, patients arrived for a visit to the doctor 3 months, 6 months, and 12 months after surgery. Further monitoring was carried out 18 months and 24 months after surgery, respectively. During the inspection the overall health status of the patient was assessed. A local state was surveyed to exclude a local recurence. In order to compare the results of the surgery treatment, the control group was organized and investigated. The control group included patients with oral cancer in advanced stage, which did not 
undergo surgical treatment. In the control group, patients, as a primary treatment, received radiotherapy with or without additional chemotherapy. Clinical data from patients included in the control group were analysed in the assessment of tumor topography, pathomorphological profile, treatment regimen, treatment outcome and survival.

\subsubsection{Quality of life assessment methodology}

Two methods of evaluation were used to assess the outcome of the oral reconstruction. One is objective - investigation done by the clinician, the other being the patient's own assessment. Functional results such as swallowing, oral occlusion (closing), mouth opening, fracture consolidation were assessed through clinical or radiology tests, while subjective, such as aesthetic results were assessed by the patient itself. These two characteristics are combined by the quality of life assessment questionnaire developed. In our study to assess the patient's quality of life (QL) of the study group following the operation, it was used the University of Washington Quality of Life Questionnaire (UW-QOL v4) (Washington) allowing to systematise and patient subjective assess the quality of their lives, which has a relatively direct correlation with the evaluation of the outcome of the patient's reconstruction. Patients who agreed to participate in the QL study had to complete the University of Washington Quality of Life Questionnaire version $4(U W-Q O L v 4)$ prior the surgery, 3 months after surgery and 12 months after surgery. Unfortunately, only 20 patients completed the study. The death of a patient, a poorly completed questionnaire, or an absence in a time-controlled survey visit, these were reasons why patients were excluded from the quality of life study.

UW-QOL v4 consists of two question groups. The first group consists of three so-called global question domains, each domain has 5-6 response options 
that are evaluated from 0 (worst) to 100 (best) points (Table 1.1). The second group of questions consists of 12 question domains that have 3 to 6 response options that are evaluated from 0 (worst) to 100 (the best) points in the appropriate order (Table 1.2).

Table 1.1

\section{Global issues domains of quality of life assessment}

\begin{tabular}{|c|c|}
\hline $\begin{array}{l}\text { Compared to the mo } \\
\text { health-related quality of life }\end{array}$ & oped cancer, how would you rate your \\
\hline Much better & 100 \\
\hline Somewhat better & 75 \\
\hline About the same & 50 \\
\hline Somewhat worse & 25 \\
\hline Much worse & 10 \\
\hline $\begin{array}{l}\text { In general, would y } \\
7 \text { days has been: }\end{array}$ & elated quality of life during the past \\
\hline Outstanding & 100 \\
\hline Very good & 80 \\
\hline Good & 60 \\
\hline Fair & 40 \\
\hline Poor & 20 \\
\hline Very poor & 0 \\
\hline $\begin{array}{l}\text { Overall quality of } 1 \\
\text { many other factors, such as } \\
\text { that are important to your e } \\
\text { contributes to your personal } \\
7 \text { days. }\end{array}$ & $\begin{array}{l}\text { physical and mental health, but also } \\
\text { ituality, or personal leisure activities } \\
\text { nsidering everything in your life that } \\
\text { overall quality of life during the past }\end{array}$ \\
\hline Outstanding & 100 \\
\hline Very good & 80 \\
\hline Good & 60 \\
\hline Fair & 40 \\
\hline Poor & 20 \\
\hline Very poor & 0 \\
\hline
\end{tabular}




\section{Domains of disease-related issues (questions about the last 7 days)}

\begin{tabular}{|l|}
\hline Pain \\
\hline I have no pain (100) \\
\hline There is mild pain not needing medication (75) \\
\hline I have moderate pain-requires regular medication (50) \\
\hline I have severe pain controlled only by prescription medicine (25) \\
\hline I have severe pain, not controlled by medication (0) \\
\hline Appearance \\
\hline There is no change in my appearance (100) \\
\hline The change in my appearance is minor (75) \\
\hline My appearance bothers me, but I remain active (50) \\
\hline I feel significantly disfigured and limit my activities due to my appearance (25) \\
\hline I cannot be with people due to my appearance (0) \\
\hline Activity \\
\hline I am as active as I have ever been (100) \\
\hline There are times when I can't keep up my old pace, but not often (75) \\
\hline I am often tired and have slowed down my activities although I still get out (50) \\
\hline I don't go out because I don't have the strength (25) \\
\hline I am usually in bed or chair and don't leave home (0) \\
\hline Recreation \\
\hline There are no limitations to recreation at home or away from home (100) \\
\hline There are a few things I can't do, but I still get out and enjoy life (75) \\
\hline There are many times when I wish I could get out more, but I'm not up to it (50) \\
\hline There are severe limitations to what I can do, mostly I stay at home and watch TV (25) \\
\hline I can't do anything enjoyable (0) \\
\hline Swallowing \\
\hline I can swallow as well as ever (100) \\
\hline I cannot swallow certain solid foods (70) \\
\hline I can only swallow liquid food. (30) \\
\hline I cannot swallow because it "goes down the wrong way" and chokes me (0) \\
\hline Chewing \\
\hline I can chew as well as ever (100) \\
\hline I can eat soft solids but cannot chew some foods (50) \\
\hline I cannot even chew soft solids (0) \\
\hline Speech \\
\hline My speech is the same as always (100) \\
\hline I have difficulty saying some words, but I can be understood over the phone (70) \\
\hline Only my family and friends can understand me (30) \\
\hline I cannot be understood (0) \\
\hline Shoulder \\
\hline I have no problem with my shoulder (100) \\
\hline My shoulder is stiff, but it has not affected my activity or strength (70) \\
\hline Pain or weakness in my shoulder has caused me to change my work/hobbies (30) \\
\hline
\end{tabular}


Table 1.2 continued

\begin{tabular}{|l|}
\hline I cannot work or do my hobbies due to problems with my shoulder $(0)$ \\
\hline Taste \\
\hline I can taste food normally (100) \\
\hline I can taste most foods normally (70) \\
\hline I can taste some foods (30) \\
\hline I cannot taste any foods $(0)$ \\
\hline Saliva \\
\hline My saliva is of normal consistency (100) \\
\hline I have less saliva than normal, but it is enough (70) \\
\hline I have too little saliva (30) \\
\hline I have no saliva $(0)$ \\
\hline Mood \\
\hline My mood is excellent and unaffected by my cancer (100) \\
\hline My mood is generally good and only occasionally affected by my cancer (75) \\
\hline I am neither in a good mood nor depressed about my cancer $(50)$ \\
\hline I am somewhat depressed about my cancer (25) \\
\hline I am extremely depressed about my cancer $(0)$ \\
\hline Anxiety \\
\hline I am not anxious about my cancer $(100)$ \\
\hline I am a little anxious about my cancer (70) \\
\hline I am anxious about my cancer (30) \\
\hline I am very anxious about my cancer $(0)$ \\
\hline
\end{tabular}

Finally, patients should note the most important problems listed below in the last 7 days (up to 3 problems):

Pain, appearance, activity, recreation, swallowing, chewing, speech, shoulder, taste, saliva, mood, anxiety.

The questionnaires obtained were analysed respectively following the UW-QOL v4 guideline (Head and Neck Surgery Outcome Tool: UW-QOL-R4).

\subsection{Statistical analysis of data}

Statistical analysis was performed using Microsoft Excel (2016) and IBM SPSS version 24.0 programmes (SPSS, Inc., Armonk, NY, USA). The results were presented as an average value of $\mathrm{M}$ and ( \pm standard deviation). The categorical 
features were expressed in terms of numbers and percentages, and analysed using Pearson's chi square or the precise test of Fisher. For the correlation analysis, the Spearman's correlation coefficient analysis $\left(\mathrm{r}_{\mathrm{s}}\right)$ was used.

For the survival analysis the Kaplan-Meier analysis with following Log-rank statistical test was used, to evaluate the difference between several survival curves a Post-hoc analysis was applied. The median (Me) and the corresponding $95 \%$ confidence level were used to evaluate the survival curve. $\mathrm{P}$-value of 0.05 was considered as statistically believable. 


\section{RESULTS}

\subsection{Clinical and cancer pathomorphological characterization of the patients}

142 patients were included in a study group that was undergoing surgical treatment with or without radiotherapy and chemotherapy. In all patients, a diagnostic biopsy was performed prior to treatment. In two patients (1\%), a basal cell carcinoma was histologically verified, while for 140 patients (99\%) a squamous cell cancer was histologically diagnosed. The control group receiving only radiotherapy with or without chemotherapy included 43 patients. In all patients, a diagnostic biopsy was performed prior to treatment. Squamous cell carcinoma (Figure 2.1) was histologically verified for all patients $(100 \%)$ in the control group.

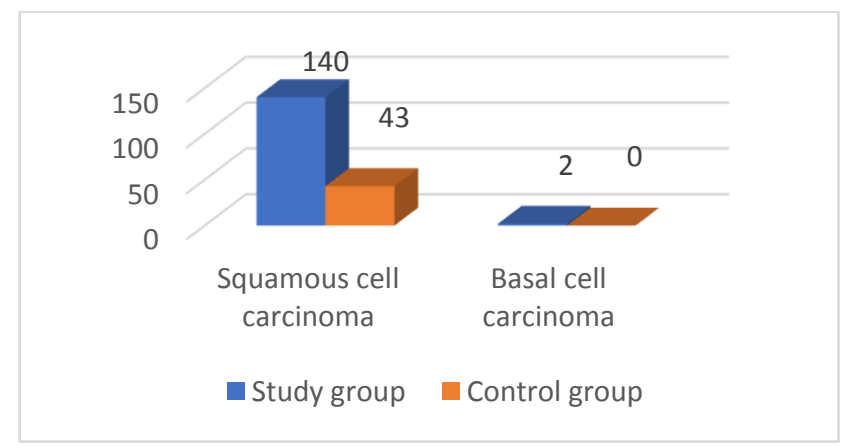
Figure 2.1 Patomorphological distribution of cancers in the study and
control groups

In study group, at the clinical assessment of primary tumor size, localization and association with surrounding tissue structures, T3 stage was diagnosed in 93 patients (65\%) and T4 stage was diagnosed in 49 patients (35\%). 
In the control group, clinically assessing the primary tumor size, the T3 stage was diagnosed in 22 patients $(51 \%)$ and the T4 stage was diagnosed in 21 subjects (49\%). See Figure 2.2.

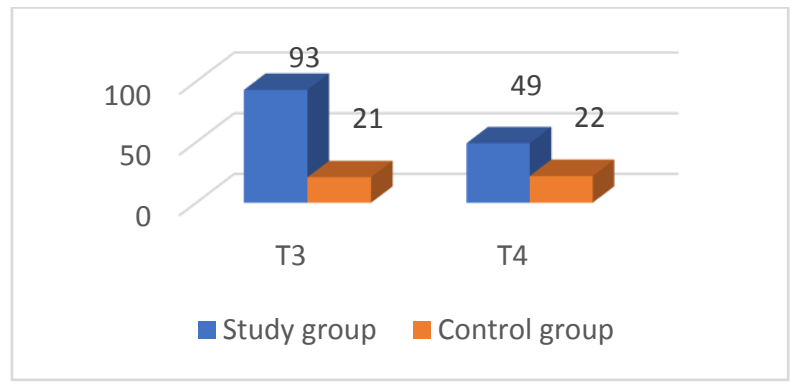

\section{Figure 2.2 Distribution of patients by $\mathbf{T}$ stage in study group and control group}

In the study group, in the assessment of the degree and size of involvement of regional lymph nodes, 54 patients (38\%) were not diagnosed with metastases in cervical lymph nodes (N0), the N1 stage was diagnosed in 45 patients (32\%), the N2 stage was identified in 42 patients (29\%), and N3 stage was observed in one patient (1\%). None of the patients included in the study group had distant metastases (M0).

In the control group, in the assessment of the degree and extent of involvement of the regional lymph nodes, no metastases in cervical lymph nodes (N0) were observed in 5 patients (12\%), the N1 stage was found in 19 patients (44\%), the N2 stage was 18 patients (40\%), and N3 was diagnosed in 1 patient (2\%). No patients enrolled in the control group had distant metastasis (M0). Graphic patient distribution by $\mathrm{N}$ stages is shown in Figure 2.3. 


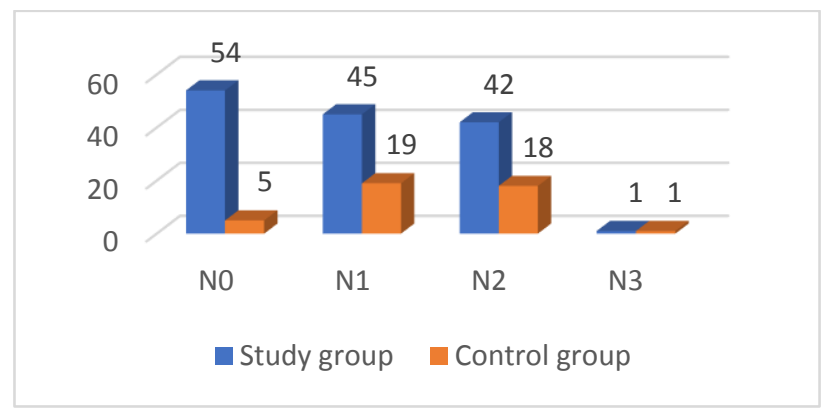

Figure 2.3 The distribution of patients by $\mathbf{N}$ in the study group and in the control group

After receiving the final pathomorphologic report using the TNM system staging, a final diagnosis stage III was set up in 70 patients in the study group, and stage IV was set up in 72 patients. Conversely, in the control group, stage III was diagnosed in 14 patients, and stage IV was diagnosed in 29 patients. The percentage of patient distribution by stages in the study group and control group is shown in Figure 2.4.

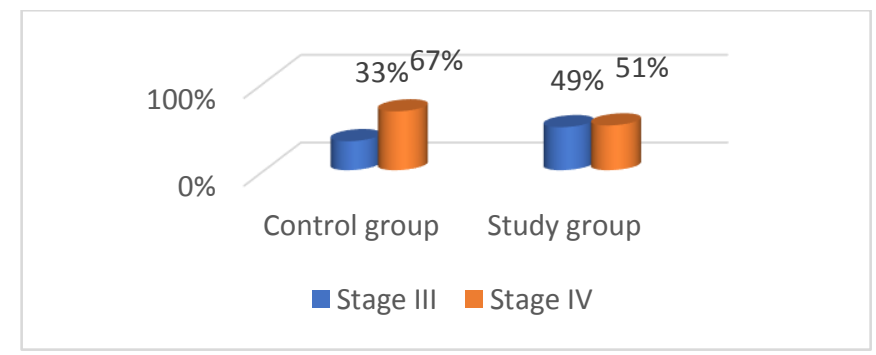

Figure 2.4 The percentage distribution of patients by stages in the control and study groups 


\subsection{Patient's sex and age}

In the study group from 142 patients, 31 subjects were females and 111 patients were males (Figure 2.5). The mean age at the start of the treatment was $58(\mathrm{SD}=11.21)$ years (from 30 years to 81 years age). The average age of women was $59(\mathrm{SD}=12.32$ ) years (from 30 years to 81 years). The male median age was $58(\mathrm{SD}=10.92)$ years (from 31 onwards to 79 years).

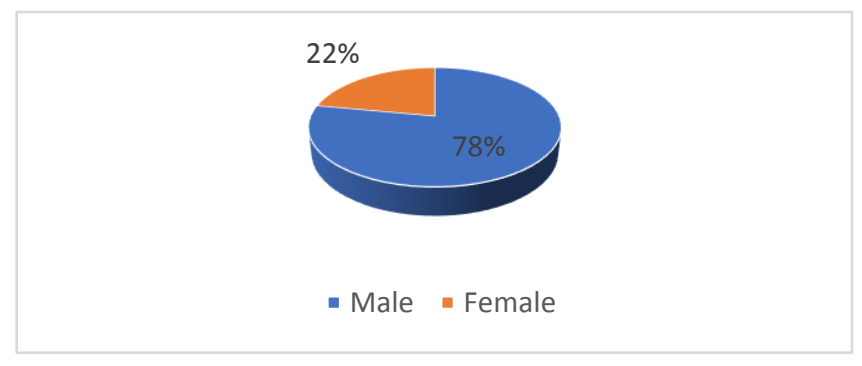

Figure 2.5 Percentage of patients' distribution by gender in the study group

In the control group from 43 patients 7 were females, but 36 patients were males. The percentage distribution of patients by gender is reflected in Figure 2.6. The average age of patients was $61(\mathrm{SD}=12.35$ ) years (from 27 years to 83 years old). The male mean age was $59(\mathrm{SD}=12.46)$ years (from 27 years to 83 years old), while the female median age was $66(\mathrm{SD}=11.08)$ years (from 45 years to 79 years). 


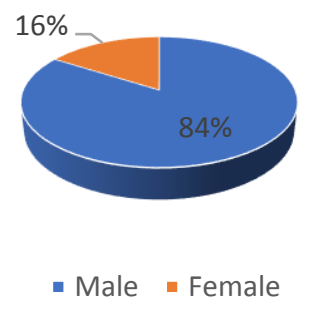

Figure 2.6 Percentage distribution of patients in the control group by gender

\subsection{Topography of the tumor}

In the study group, when evaluating tumor localization in oral cavity, in 19 patients the tumor was localized in the floor of mouth, 53 patients had a tumor localized in the floor of mouth with the tongue involvement, and 20 patients had a tumor in the tongue, in 6 patients localization was floor of the mouth with the lower jaw involvement, in 19 patients, the tumor localization was the lower jaw, 8 patients had a tumor localized in the floor of mouth with cheek involvement, in 7 patients, the tumor was on the cheek, 8 patients had a tumor originating from lips, for two patients, tumor localization was the upper jaw.

When evaluating oral tumor localization in the control group, in 4 patients the tumor was localized in the floor of mouth, 12 patients had tumor localized in the tongue, one patient had tumor localized in the cheek, 6 patients had a tumor localized in the floor of mouth with tongue involvement, one patient had a tumor located in the floor of the mouth with the lower jaw involvement, 9 patients had a tumor localized in palatine (tonsille palatine) and 10 patients had the tumor localized in palatine with the tongue involvement. Tumor topography data are summarized in Table 2.1. 


\section{Tumor topography for study group and control group}

\begin{tabular}{|l|c|c|}
\hline $\begin{array}{c}\text { Localization of } \\
\text { tumor }\end{array}$ & $\begin{array}{c}\text { Involvement of regional } \\
\text { lymph nodes in study group, } \\
\mathrm{N}(\%)\end{array}$ & $\begin{array}{c}\text { Involvement of regional } \\
\text { lymph nodes in control group, } \\
\mathrm{N}(\%)\end{array}$ \\
\hline Floor of mouth & $19(13)$ & $4(9)$ \\
\hline Tongue & $20(14)$ & $12(28)$ \\
\hline $\begin{array}{l}\text { Floor of mouth } \\
\text { and tongue }\end{array}$ & $53(38)$ & $6(14)$ \\
\hline Cheek & $7(5)$ & $1(2)$ \\
\hline $\begin{array}{l}\text { Floor of mouth } \\
\text { and cheek }\end{array}$ & $8(6)$ & 0 \\
\hline Lower jaw & $19(13)$ & $1(2)$ \\
\hline $\begin{array}{l}\text { Floor of mouth } \\
\text { and lower jaw }\end{array}$ & $6(4)$ & $0(0)$ \\
\hline Upper jaw & $2(1)$ & $0(0)$ \\
\hline Lip & $8(6)$ & $9(21)$ \\
\hline Palatine & $0(0)$ & $10(24)$ \\
\hline $\begin{array}{l}\text { Palatine and } \\
\text { tongue }\end{array}$ & $0(0)$ & 0 \\
\hline
\end{tabular}

\subsection{Classification by TNM system}

Analyzing the final pathomorphological reports of 142 patients included in the study group it was found that two patients had a histologically verified basal cell carcinoma, while 140 patients had a histologically diagnosed squamous cell cancer. In histological evaluation of the primary tumor size, T3 was diagnosed in 93 patients (65\%), T4 was diagnosed in 49 patients (35\%).

In evaluating the degree and magnitude of involvement of regional lymph nodes, in 54 patients metastases in lymph nodes were not diagnosed (N0), N1 stage was detected in 45 patients, the N2 stage was diagnosed in 42 patients and N3 stage was established in one patient. A comparison of the patient's diagnosis before surgery using the TNM system classification with the post-operative diagnosis it was established that the diagnoses coincided for all patients. 
For none of the patients included in the study group had diagnosed distant metastases (M0).

The control group included 43 patients receiving radiotherapy with or without chemotherapy. Squamous cell carcinoma was histologically verified in all patients. Evaluating the primary tumor size T3 was diagnosed in 21 patients and T4 was diagnosed in 22 subjects. Assessing the degree and extent of involvement of regional lymph nodes, no metastases in cervical lymph nodes were found in 5 patients (N0), the N1 stage was found in 19 patients, the N2 stage was observed in 18 patients, N3 stage was diagnosed in 1 patient. None patient enrolled in the control group had distant metastases (M0).

\subsection{The relationship of tumor localization with a frequency of the cervical lymph nodes involvement}

When analysing the relationship between tumor localization and tumor metastasation, tumor localization sites were conditionally divided into 3 groups. The first group is where the tumor is localized in the floor of the mouth. The second group is characterized by the tumor is localized in the tongue; in the third group were included tumors localized into other parts of the oral cavity. The tumors localized both in the tongue and in the floor of the mouth were added to the tongue localization, basing on the fact that literature data indicates the most pronounced tendency of the tongue tumors to metastase in the cervical lymph nodes.

Summarizing the obtained data, the oral cancer in the control group localized in the floor of the mouth had metastases in cervical lymph nodes in $60 \%$ of the cases, whereas in the study group, the cervical lymph nodes involvement was observed in $65 \%$ of cases. 
The tumors, which were localized in the tongue, in control group were metastasised in cervical lymph nodes in $89 \%$ of the cases, and in the study group - in $68 \%$ of the cases.

For the tumors that were identified as having other localizations, in the control group the cervical metastases were found in $100 \%$ cases, whereas in the study group cervical metastases were found in $30 \%$ cases. No statistically significant association between localization and $\mathrm{N}$ stage $(\mathrm{P}=0.24)$ was found in the statistical analysis, but there is a tendency that the tongue localization has the highest metastatic tendency. The number of patients whose cancer is localized in the tongue and has metastases in the cervical lymph nodes is 2.6 times higher than the number of patients who have no neck lymph nodes metastases, while for the cancer in the floor of the mouth this proportion is 1.71 times, and for other locations -1.25 times. The association of tumor localization with the frequency of metastases in cervical lymph nodes in the patients included in the study is shown in Figure 2.7.

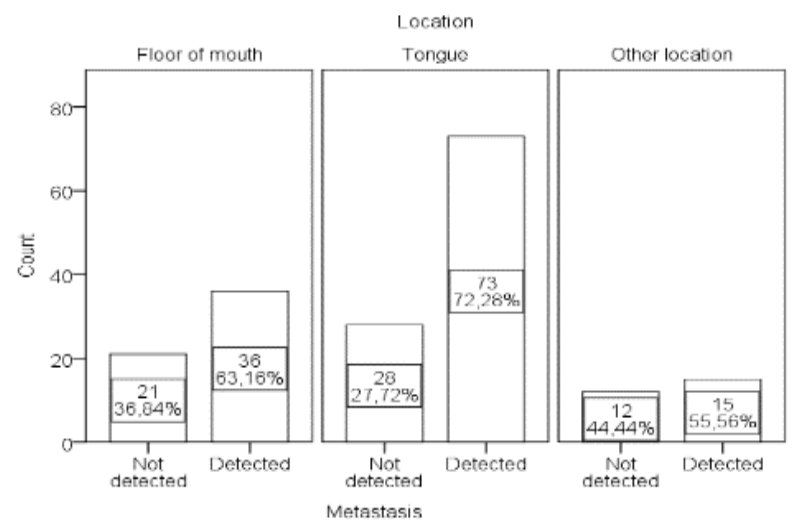

Figure 2.7 Association of tumor localization with frequency of cervical lymph node metastasis in patients involved in the study 
Conversely, the relationship of tumor localization with the extent of cervical lymph nodes involvement $(\mathrm{N})$ in the patients included in the study is illustrated in Figure 2.8.

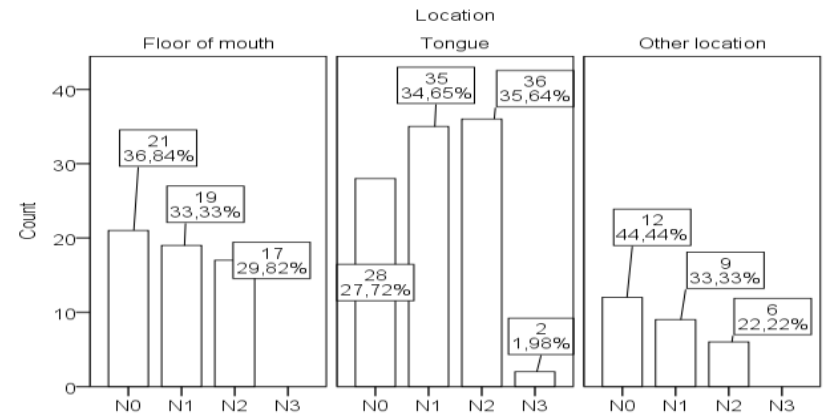

Figure 2.8 The association of tumor localization with $\mathbf{N}$ stage in patients enrolled in the study

The association of tumor localization and frequency of metastases in percentage distribution in the study and control groups is shown in Figure 2.9.

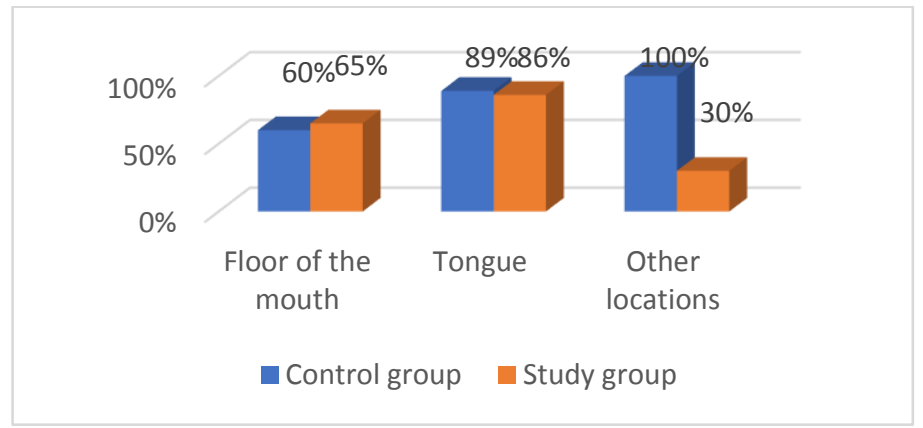

Figure 2.9 Dependance of the cervical metastasis frequency of advanced stage oral cancer by tumor location in control and study groups 


\subsection{Medical comorbidities}

From 142 patients who were enrolled in the study group there were no comorbidities 29 of patients. 113 patients were found to have 224 illnesses. 40 patients were diagnosed with single disease and 73 patients were found to have two or more chronic conditions.

The most commonly found disease was the smoker's bronchitis in 80 patients. The second most frequent chronic condition was arterial hypertension -52 patients. Coronary heart disease was detected in 36 patients. Diabetes mellitus in 12 patients, central nervous system (CNS) disease in 11 patients, alcoholism in 9 patients, liver disease in 6 patients, atherosclerosis diagnosis was settled in 5 patients, gastric ulcer disease in 4 patients, prostate adenoma and rheumatoid arthritis in 2 patients.

Five patients had a history of previous diagnosis and treatment of tumor in another localization. Tumors, who had a history of treatment in patients were breast cancer, lung cancer, cervical cancer, skin cancer and non-Hodgkin's lymphoma. At the time the patients were included in the study, they were considered to be disease free from these tumors.

Analysis of data from 6 patients, who died, in the study group showed that all six patients had multiple comorbidities. Four patients had arterial hypertension and four patients had smoker bronchitis. Two patients had coronary heart disease; one patient had diabetes mellitus, one atherosclerosis, and one alcoholism. The percentage distribution of comorbidities of patients, who died, is shown in Figure 2.10. 


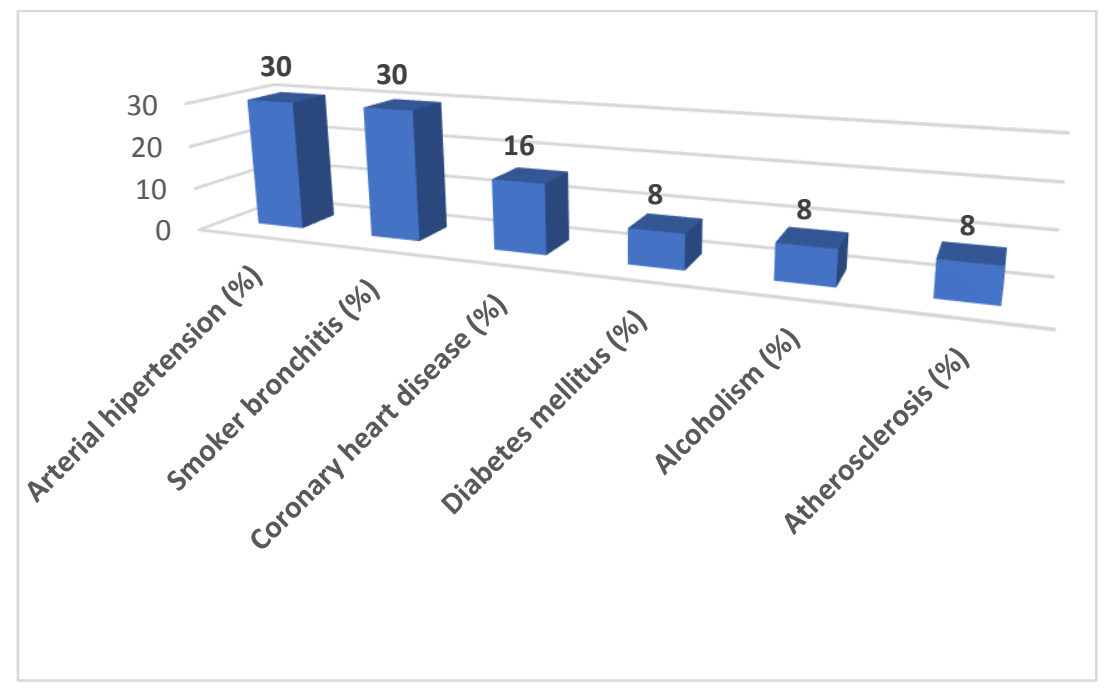

Figure 2.10 Percentage distribution of the comorbidities in the patient's group, who died

If comorbidities for the patients, who developed complications after surgery in the study group are being analysed, it was found that of the 26 patients who developed post-operative complications, five patients were diagnosed no comorbidities. 6 patients had single disease, but 19 patients had multiple comorbidities. The most commonly diagnosed disease was the smoker's bronchitis in 17 cases; arterial hypertension was observed in 10 cases, coronary heart disease in 8 cases, diabetes mellitus and gastric ulcer in two cases. Atherosclerosis, CNS disease, prostate adenomas and alcoholism were found in one case. When analysing the relationship of complications with comorbidities, it was obtained that the complications for patients with comorbidities were for found for almost fifth part of them - 26 (18.31\%). However, 88 (61.97\%) patients had comorbidities, but there were no complications, while $23(16.20 \%)$ had no comorbidities and no complications. 5 (3.52\%) of the patients had no chronic condition but had complications (Figure 2.11). A statistically significant 
association between comorbidities and complications was not observed $(\mathrm{p}=0.57)$, however, in estimating the odds ratio, a tendency was gained: those with comorbidities 1.38 times more likely have complications.

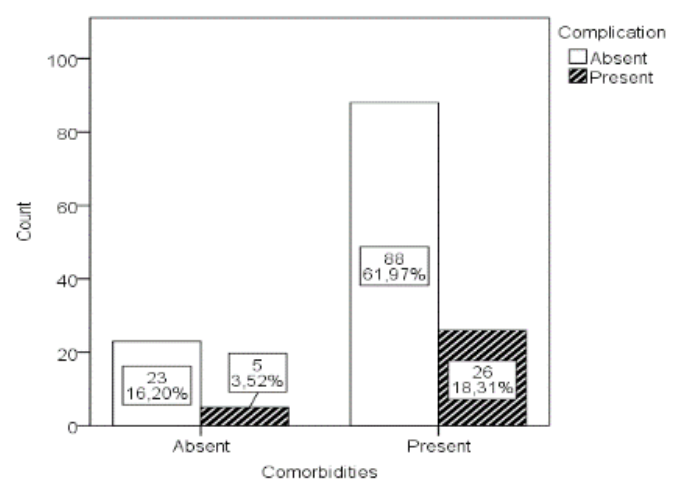

Figure 2.11 Comorbidities and complications number distribution in the control and study group patients

\subsection{Analysis of patients' survival}

To assess the survival of patients, the study group and the control group were analysed assessing the patient's gender, position of resection lines and tumor type, its stage's effect on survival. Analysis of patients treated both in the study group and in the control group yielded a total survival curve as shown in Figure 2.12. In all patients treated both in the control group and in the study group, the median survival was 2.25 years (95\% CI: $1.52-2.98$ years). 


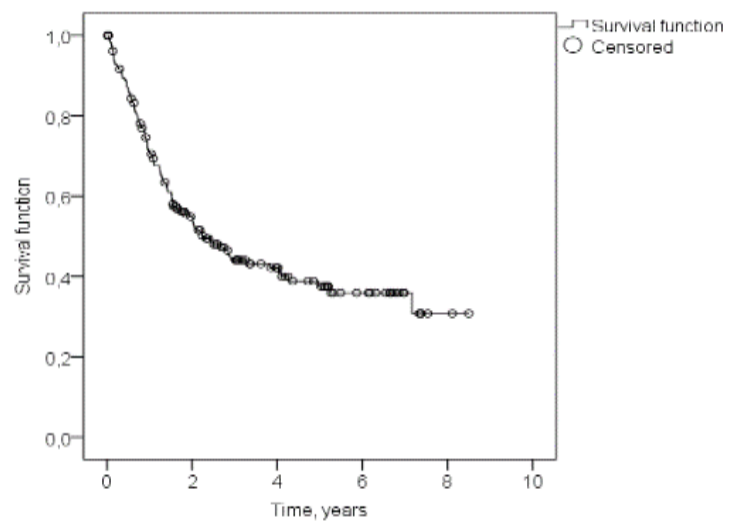

Figure 2.12 Total survival curve

An analysis of the survival rate of the control group and the study group showed that the study group's survival shows significant improvement compared with the control group (Figure 2.13). The study group's 2-year survival was 60\%, while in the control group it was $30 \%$. In contrast, the five-year survival in study group attained $42 \%$, but in the control group no patients were alive after five years.

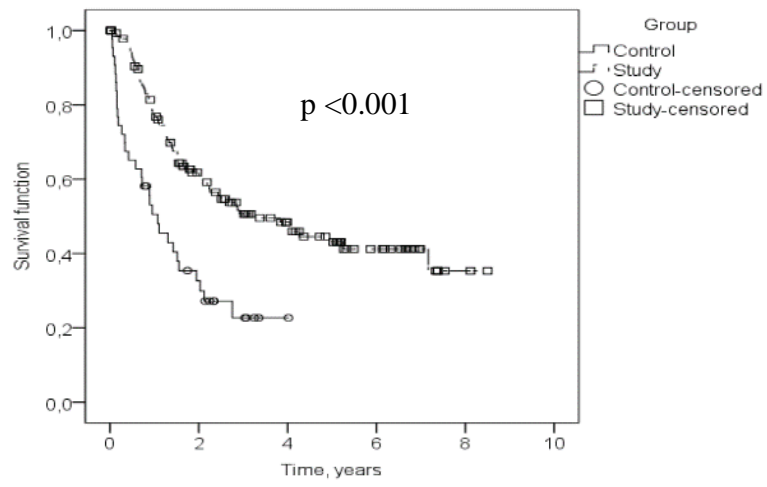

Figure 2.13 Kaplan-Meier survival curves for study group and control group 
In the Log-rank statistical test analysis, it was found that the survival curve for the control group ( $\mathrm{Me}=1.07$ years; $95 \% \mathrm{CI}$ : $0.58-1.57$ years) and the study group $(\mathrm{Me}=3.27$ years; 95\% CI: $1.78-4.76$ years) were statistically significantly different $(\mathrm{p}<0.001)$.

In the study was analysed the effect of patient's gender, excision lines, tumor size ( $\mathrm{T}$ stage), lymph nodes involvement ( $\mathrm{N}$ stage) and tumor differentiation (Grade) on the 2-year and 5-year survival rate of patients in the study and control groups.

A summary of the factor effects for 2-year and 5-year survival in patients in the control group and study group is shown in Table 2.2.

Table 2.2

\section{Summary of effects of various factors on 2-year and 5-year survival in patients in the control group and study group}

\begin{tabular}{|l|c|c|c|c|}
\hline \multirow{2}{*}{$\begin{array}{c}\text { Influencing } \\
\text { factors }\end{array}$} & \multicolumn{2}{|c|}{ 2-year survival } & \multicolumn{2}{c|}{ 5-year survival } \\
\cline { 2 - 5 } & $\begin{array}{c}\text { Control group } \\
(\%)\end{array}$ & $\begin{array}{c}\text { Study group } \\
(\%)\end{array}$ & $\begin{array}{c}\text { Control group } \\
(\%)\end{array}$ & $\begin{array}{c}\text { Study group } \\
(\%)\end{array}$ \\
\hline Female & 65 & 65 & 0 & 45 \\
\hline Male & 25 & 60 & 0 & 42 \\
\hline T3 & 35 & 60 & 0 & 41 \\
\hline T4 & 21 & 60 & 0 & 50 \\
\hline N0 & 58 & 75 & 0 & 65 \\
\hline N1 & 25 & 62 & 0 & 38 \\
\hline N2 & 30 & 40 & 0 & 25 \\
\hline Grade 1 & 25 & 100 & 0 & 100 \\
\hline Grade 2 & 32 & 55 & 0 & 38 \\
\hline Grade 3 & 45 & 61 & 0 & 45 \\
\hline Stage III & 42 & 70 & 0 & 52 \\
\hline Stage IV & 28 & 53 & 0 & 37 \\
\hline $\begin{array}{l}\text { Overall } \\
\text { survival }\end{array}$ & 30 & 60 & 0 & 42 \\
\hline
\end{tabular}




\subsection{Assessment of the quality of life}

Of the 142 patients enrolled in the study, in the quality of life study agreed to take part 36 patients undergoing the oral cancer ablation and a reconstruction of the oral cavity with a microvascular flap. The study was completed by 18 males (90\%) and two females (10\%). The median age at the time of surgery was $53(\mathrm{SD}=10.40)$ years (from 34 to 76 years).

Using the UW-QOL data presentation guidelines (Head and Neck Surgery Outcome Tool: UW-QOL-R4), the following results were obtained from the global question domains. Table 2.3 represents the data before the operation and a year after the operation in the domains of global issues.

Table 2.3

UW-QOL results of global question domains before operation and one year after surgery

\begin{tabular}{|l|c|c|c|c|}
\hline \multirow{2}{*}{ UW-QOL } & \multicolumn{2}{|c|}{ Before surgery } & \multicolumn{2}{c|}{ One year after surgery } \\
\cline { 2 - 5 } & $\begin{array}{c}\text { Mean (SE } \\
\text { of mean) }\end{array}$ & $\begin{array}{c}\text { Best Scores } \\
(\%)\end{array}$ & $\begin{array}{c}\text { Mean (SE } \\
\text { of mean) }\end{array}$ & $\begin{array}{c}\text { Best } \\
\text { Scores (\%) }\end{array}$ \\
\hline $\begin{array}{l}\text { A. Health-related QOL } \\
\text { compared to month } \\
\text { before had cancer }\end{array}$ & 14 & 15 & 26 & 25 \\
\hline $\begin{array}{l}\text { B. Health-related QOL } \\
\text { during the past 7 days }\end{array}$ & 21 & 15 & 64 & 75 \\
\hline $\begin{array}{l}\text { C. Overall QOL during } \\
\text { the past 7 days }\end{array}$ & 24 & 15 & 58 & 75 \\
\hline
\end{tabular}

When evaluating the findings, it is evident that in domain A the average score increased from 14 points to 26 points, while the percentage of best possible responses increased from 15 to $25 \%$. In domain $\mathrm{B}$, the average score has increased from 21 points to 64 points, but the percentage of the best possible answers has increased from 15 to $75 \%$. By contrast, in the $\mathrm{C}$ domain, the average 
score increased from 24 points to 58 points, while the percentage of the best possible responses has increased from 15 to $75 \%$.

When using the UW-QOL data presentation guidelines, the following results of the disease-related issues domains were obtained: Table 2.3 shows the data before the operation and data a year after the operation. Analysing of the results of the disease-related issues domains it is visible that the average score after surgery compared with period before the operation has increased in domains - activity, mood, anxiety. A statistically significant average score has increased in the domain - pain $(\mathrm{p}=0.001)$, from 58.75 points to 91 point. The number of points before and after surgery in shoulder $(\mathrm{p}=0.08)$ and saliva $(\mathrm{p}=0.68)$ domains has not been statistically significantly altered. Score decreased in domains - appearance $(\mathrm{p}=0.08)$, recreation $(\mathrm{p}=0.01)$, swallowing $(\mathrm{p}=0.1)$, speech $(p=0.005)$, and taste $(p<0.001)$. The most pronounced deterioration is in the chewing domain $(\mathrm{p}=0.1)$ - from 40 points to 13 points. The percentage of the best possible response rates has increased significantly in the pain domain - from 10 to $70 \%$. The highest decrease in the percentage of the best possible answers is in the domain the taste - from 80 to $25 \%$. The percentages of the best possible answers, before and after surgery, remain completely constant in the domain shoulder $-100 \%$, and the saliva $-90 \%$.

In evaluating the QOL data, it was found that domains - shoulder $(\mathrm{p}=0.08)$ and saliva $(\mathrm{p}=0.68)$ were maintained without modification. Statistically significant $(\mathrm{p}<0.05)$ improvement there are in domains - pain, mood and anxiety. A statistically believable $(\mathrm{p}<0.05)$ deterioration is in the domains - chewing, recreation, speech and taste. Decreasing trend, but without statistical reliability $(\mathrm{p}>0.05)$ was found in domains - appearance, activity, swallowing. See Figure 2.14. 


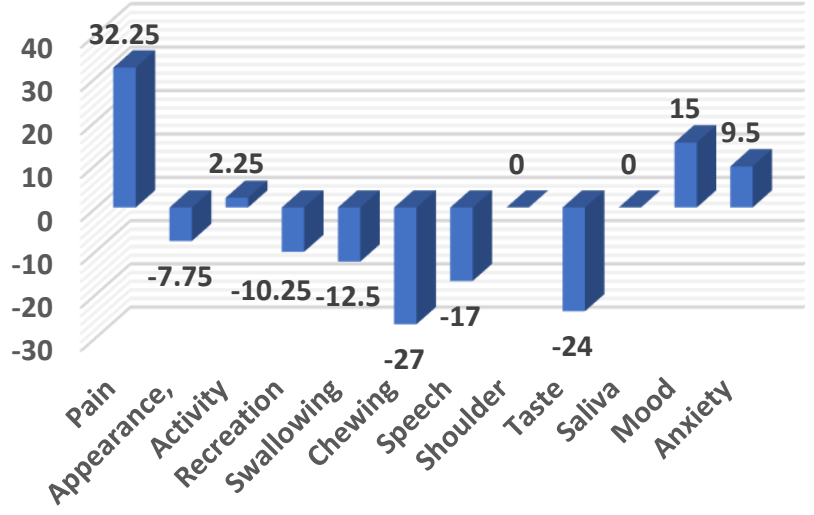

Figure 2.14 Changes of the result of disease related domains during the year

Patients also noted three key problems regarding the importance priorities during last seven days. As the first they noted the problem that was the biggest concern, then the second most important problem, and then the third most important problem. Patients were questioned three periods of time - before the operation, three months after the operation and the year after the operation. The distribution of positions was created by adding up answers and putting such problem in the first place, which concerns most the highest number of patients surveyed. An analysis of the patient's responses resulted in the following distribution of positions. See Table 2.4.

Table 2.4

Distribution of positions for the most important problems that deteriorate the quality of life of patients prior to surgery, 3 months after surgery and one year after surgery

\begin{tabular}{|l|c|c|c|}
\hline UW-QOL & $\begin{array}{c}\text { Position before the } \\
\text { operation }\end{array}$ & $\begin{array}{c}\text { Position three months } \\
\text { after the surgery }\end{array}$ & $\begin{array}{c}\text { Position a year after } \\
\text { the surgery }\end{array}$ \\
\hline Pain & 3 & 7 & $8=^{*}$ \\
\hline Appearance & 7 & $8=$ & 7 \\
\hline
\end{tabular}


Table 2.4 continued

\begin{tabular}{|l|c|c|c|}
\hline UW-QOL & $\begin{array}{c}\text { Position before the } \\
\text { operation }\end{array}$ & $\begin{array}{c}\text { Position three months } \\
\text { after the surgery }\end{array}$ & $\begin{array}{c}\text { Position a year after } \\
\text { the surgery }\end{array}$ \\
\hline Activity & $4=$ & $5=$ & $4=$ \\
\hline Recreation & $11=$ & 12 & $8=$ \\
\hline Swallowing & $4=$ & $2=$ & 3 \\
\hline Chewing & 1 & 1 & 1 \\
\hline Speech & 8 & $2=$ & 2 \\
\hline Shoulder & $11=$ & $10=$ & 12 \\
\hline Taste & $9=$ & 4 & $4=$ \\
\hline Saliva & $9=$ & $10=$ & $8=$ \\
\hline Mood & $4=$ & $8=$ & $8=$ \\
\hline Anxiety & 2 & $5=$ & 6 \\
\hline
\end{tabular}

* indicates that the particular position is divided by several domains according to importance

From the obtained results it is evident that before surgery the three most important problems for patients were chewing, anxiety, and pain. Three months after the operation and the year after the operation the three most important problems that worsen the quality of life were chewing, speech and swallowing. By analysing all the controlled time spans, chewing is the most important problem, which impairs the quality of life throughout the treatment process and during the further observation period of the patient.

\subsection{Application of methods of microvascular reconstruction}

For all 142 patients in the study group, a single stage oral reconstruction with microvascular flaps was performed. A total of 111 soft tissue reconstructions (78\%) and 31 complex reconstructions of bone and soft tissues were performed $(22 \%)$.

In total, 144 microvascular flaps were transplanted. Of these 113 flaps were fasciocutaneous flaps, 31 was osteocutaneous flaps. 
Performing the oral soft tissue reconstructions, the most used fasciocutaneous flap was radial forearm flap $-69 \%$ of the cases, the second most commonly applied was lateral arm flap $-29 \%$ of the cases and ALT was transplanted in $2 \%$ of cases.

Performing complex soft and bone tissues oral cavity reconstructions, the most commonly used osteocutaneous flap was the vascularised free fibula flap, in $94 \%$ of cases, while in $2 \%$ of cases was transplanted osteocutaneous scapula free flap and in $2 \%$ cases - iliac crest (crista iliaca) flap.

\subsection{Analysis of the patients' hospital stay in the study group}

The average hospital stay for operated patients was 20.5 days (from 8 to 44 days). There was no statistically significant correlation $(\mathrm{p}>0.05)$ between the age of patients and the hospital stay. However, the hospital stay was correlated with the size of the tumor. In patients with a larger tumor size, the lengh of hospital stay was increased (Figure 2.15).

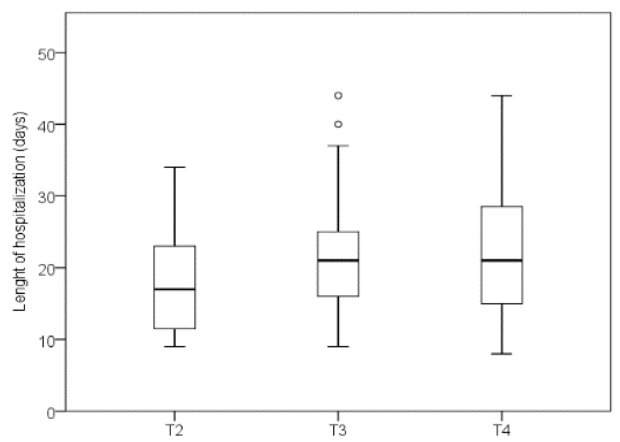

Figure 2.15. Changes in the length of hospitalization (days) at different $T$-stages in the study group 
In the correlation analysis between $\mathrm{T}$ and hospital stay, a positive, weak and statistically reliable correlation was obtained $\left(r_{s}=0.16 ; p=0.04\right)$.

\subsection{Analysis of post-operative complications in the study group}

Complications in the post-operative period can be conditionally divided into major and minor complications. The major complications mean a deterioration of the patient's general health in the postoperative period, which can lead to death of the patient, and the necrosis of the transplanted tissue, which in turn if delayed treated can provoke a number of other complications that may endanger the life of the patient.

Of the 142 patients operated, 6 patients died in the postoperative period. 4 patients were undergoing a complex reconstruction of the oral cavity with an osteocutaneous flap, while two patients had undergone soft tissue reconstruction with a fasciocutaneous flap.

Of the total transplanted 144 flaps 142 flaps were taken. Flap success rate was $98.6 \%$. Three patients (2\%) showed circulatory disorders in the transplanted flap during the postoperative period. In two cases (67\%) it was an osteocutaneous flap, in one case (33\%) the fasciocutaneous flap. In all three patients veinous thrombosis was detected. In all cases, flap salvage operations was carried out. Performed re-exploration in one case was succesful, but in two cases failed and flap was lost. For those patients, a salvage oral reconstruction with another flap was performed. Minor complications in the operated patients were wound haematoma, healing by secondary intention and marginal wound necrosis. Of the 142 operated patients, the following complications were observed in 17 patients. In 14 cases, a haematoma was identified which required repeated surgery to 
remove haematoma. One patient had oral wound healing by secondary intention. Two patients had marginal necrosis of the wound.

\subsection{Effect of reconstruction type on the frequency of post-operative complications}

Among the patients in the study group undergoing the soft tissue reconstruction - 91 patients $(64.08 \%)$ had no complications, while 20 patients (14.08\%) had complications. On the other hand, in patients undergoing complex reconstruction of soft and bone tissue, 20 patients (14.08\%) had no complications and 11 patients $(7.75 \%)$ had complications. A statistically significant association $(\mathrm{p}=0.03)$ was observed at statistical analysis of reconstruction type and complications. Prospects that patients with complex reconstruction will have complications are 2.50 (95\% CI: 1.03-6.04) times higher compared to soft tissue reconstruction. 


\section{DISCUSSION}

The oral cancer ability to stay asymptomatic for long time and the early tendency to metastasise in cervical lymph nodes result in a delayed diagnosis of the disease. In countries with developed economies, oral cancer is diagnosed more rarely in the advanced stages than in countries with poorly developed economies. This is due not only to access to healthcare but also to public health education. The clinical course of cancer is unfortunately still a problem for early diagnosis, which has led to a significant proportion of oral cancer even in developed countries. According to CDPC data in 2016, 66\% of patients were diagnosed with an advanced oral cancer.

In the world, according to literature data, the average age of falling ill for patients with oral cancer is 60 years. The average age of all enrolled patients in the study group was 58 years (from 30 to 81 years), women had an average age of one year more - 59 years. Comparing the data of our study with CDPC data, it is visible that in our study the incidences of both sexes essentially coincide about the relevant time period.

In the world, for males oral cancer is three times more common than for females (Weatherspoon, Chattopadhyay et al. 2015). Of the patients in our study, males were 3.5 times more frequent in the study group and 5 times more frequent in the control group. By analysing the type of pathomorphological tumors in the Latvian population, this tumor type does not differ from world literature data (Montero and Patel 2015), as in the study group 99\% were diagnosed with squamous cell carcinoma, while in the control group, squamous cell carcinoma was in all cases $(100 \%)$.

When tumor localization in oral cavity is analysed, then data of our study differs from other countries ' data. According to the literature, $90 \%$ of tumors were localized in the tongue and in the floor of the mouth (Montero and Patel 
2015), but in our study group, the tumor was localized in the floor of the mouth and in the tongue in $75 \%$ of cases. Subsequently, in the control group, the tumor was localized in the floor of the mouth and tongue in $53 \%$ of cases. This is due to the fact that in the early stages the primary localization of the tumor is usually easy to identify, a small ulcer with clear borders usually does not cause problems to localize and correctly define it. Conversely, in advanced stages, when the tumor has been affected by several structures such as the tongue, the floor of the mouth, and gums or cheeks, the destruction of the tumor with local inflammation is observed, and precise definition of the primary tumour is often difficult.

When the pathomorphological results of tumors are analysed, it is concluded that the TNM system allows the precise assessment of the primary tumor size, the state of the lymph nodes and the presence or absence of the distant metastases. Our study shows that in the advanced stages of oral tumors, there was no case of change of diagnosis after final histology report, suggesting that the primary diagnosis of the disease was relatively accurate in the hands of experienced specialists.

The primary tumor evaluation is an important condition for successful development of the treatment plan. The accurate assessment of the tumor localization and its relationship with the surrounding structures allow properly plan the extent of operation, the type of reconstruction required and the additional manipulations, which will provide an easily and reliably controlled postoperative recovery period. Despite the complex anatomical structure of the oral cavity, the wide available reconstruction options of the oral cavity give the surgeon the opportunity to radically excise the tumor. Our data show that in the study group only four patients had positive excision lines. In the remaining 138 cases, the tumor was radically removed with clean margins.

Localization of tumor in the oral cavity is not only important for the development of tactics of the primary tumor treatment, but also for the 
assessment of the metastases in lymph nodes. As evidenced by the literature data (Shah, Candela et al. 1990, Bittar, Ferraro et al. 2016), the status of cervical lymph nodes and their exact diagnostics mostly affect of the patient's survival prognosis. Knowing the way, how the metastasization in the cervical lymph nodes proceeds, the most appropriate type of neck dissection can be chosen. In patients with clinically negative cervical lymph nodes the greatest chance for metastases is at level I-III (Shah, Candela et al. 1990). Rarely, metastasis can also be found at level IV, especially if the tumor is localized in the anterior part of the tongue. Metastases at level V are rare (1\%), even if the patient has cervical metastases at other levels. Of all oral tumors, directly tongue tumors have the greatest tendency to metastasize in cervical lymph nodes and the tumor thickness is the most important prognostic factor in evaluating the risk of tumor metastazation (Fakih, Rao et al. 1989, Montero and Patel 2015). Our study confirms that a tumor localized in the tongue has a high tendency to become metastasized to the lymph nodes of the neck. The control group cervical lymph node metastases had in $89 \%$ and the study group in $86 \%$ of cases.

Shah J.P. et al. points out that in tumors with a depth of less than $2 \mathrm{~mm}$ neck metastasization risk at the cervical lymph nodes is $13 \%$, if the tumor depth reaches $3-8 \mathrm{~mm}$, then the risk of metastasization in the cervical lymph nodes is $46 \%$, but if it is more than $8 \mathrm{~mm}$, the risk of metastasization at the neck lymph nodes reaches $65 \%$. It would be interesting to compare these results with the data of our study, but unfortunately, the pathomorphological analysis carried out in Latvia most often describe the size of the tumor, but not the thickness, so to examine the relationship between the thickness of the tumor and the frequency of metastasization in the neck lymph nodes was not possible.

In an analysis of the localization of oral cancer with a tendency to metastasize in cervical lymph nodes, it was objectively possible to evaluate only the study group, as the control group did not have any neck disections. 
Conversely, the study group's 139 patients had a cervical lymphadenectomy, and its only three patients were not undergoing cervical lymph-adenectomy.

Interestingly, of the 73 patients in the study group, which had diagnosed tumor in the tongue, metastases in cervical lymph nodes were diagnosed in most of the patients -50 patients, of which $\mathrm{T} 1$ was in 25 patients, $\mathrm{T} 2$ was in 24 patients and T3 was in one patient. Conversely, 23 patients were not diagnosed with metastases in cervical lymph nodes.

In the control group from 43 patients, 28 patients had tumor localization on the tongue. Of these 28 patients, no metastases in cervical lymph nodes were detected in three patients. 11 patients were diagnosed with N1, 13 patients were diagnosed with $\mathrm{N} 2$, and one patient with $\mathrm{N} 3$. The findings suggest that the tumor localized in the tongue has a high tendency to metastasize in cervical lymph nodes.

In order to assess the relevance of the potential impact factors related to the results of surgery and the frequency of complications patients' comorbidities were analysed. In the study group of 142 patients, only $20 \%$ of patients were found no comorbidities. In $80 \%$ of patients were detected 224 diseases. More than half of the study group had multiple comorbidities. The most common disease was smoking bronchitis, reaching $36 \%$ of the number of patients in the study group. The fact that smoker bronchitis is a leader among diseases is not surprising, knowing that one of the main etiologies in the oral cancer is smoking (Lambert, Sauvaget et al. 2011, Kumar, Nanavati et al. 2016).

The second most frequent disease was arterial hypertension in $23 \%$ and coronary disease in $16 \%$ of patients followed. It correlates with the proportion of these diseases in the population both in Latvia and globally. The incidence of other diseases was insignificant, but there was an important fact, that in $2 \%$ of the patients in the study group had cancer of other localization, which was diagnosed and treated before the diagnosis of oral cancer was settled. In patients 
with oral cancer the risk of getting a second primary head and neck cancer is about $4-7 \%$ (Leon, Martinez et al. 2012), but there is no accurate data on how high the risk is of suffering from another cancer of other localization.

The median survival for all treated patients in the study was 2.25 years. When comparing survival between men and women, women have been found to be $5 \%$ higher in the two-year survival rate than in males, while the 5-year survival rate is $3 \%$ higher, which is not a significant difference. On the other hand, in the control group, 2-year survival remains $65 \%$, while men have now only $25 \%$. In the control group, neither men nor women lived for five years. Results suggest that patient gender has no significant effect on survival. The $40 \%$ difference in the control group on 2-year survival is attributable to the small proportion of women in the control group. If men were able to obtain statistically significant differences in the study and control groups, no statistically significant and correct calculations could be performed in women due to the low number of patients.

In order to assess whether the duration of life of the surgically treated patients was longer than in patients who had not received surgery, the study group and the control group were compared by the duration of survival.

Our study shows that in patients who were only using radiotherapy with or without chemotherapy, a 2-year survival rate was for $30 \%$ lower, as in patients who had surgery. In patients undergoing tumor excision, $42 \%$ lived for five years. Of the 43 patients treated with radiotherapy, no patients lived for five years.

This confirms the fact that surgical treatment is still the basic method of treatment for patients with oral cancer (Smee, Broadley et al. 2012) and patients should be motivated not to refuse the surgery as this may significantly prolong their survival.

An analysis of the effect of tumor size on patient survival showed that in patients with T3 tumor, a 2-year survival in the study group was $25 \%$ higher than 
in the control group, while a 5-year survival in the study group reached to $41 \%$, but in the control group any patient did survive for five years. In patients with T4, a 2-year survival rate was for $39 \%$ higher than in the control group. In contrast, the 5-year survival rate was 50\% in the study group, but no patient lived for five years in the control group. The comparison of T3 with $\mathrm{T} 4$ has shown that tumor size does not play a decisive role in the survival of patients. This confirms the fact that the size of the tumour does not play any decisive role in the survival of the patient (Punhani, Dongarwar et al. 2017).

An analysis of the effect of tumor differentiation degree on patient survival showed that the degree of tumor differentiation was a significant prognostic factor, but not conclusive. In the control group, the 2-year survival rate in patients with Grade 1 was for $20 \%$ lower than Grade 3, which indicates that radiotherapy is an effective treatment for low-differentiated tumor. It is indicated as additional treatment for patients undergoing surgical treatment. In the study group for patients with high differentiation degree (Grade 1) tumor levels, 2-year and 5-year survival was $100 \%$. In patients with low differentiation degree grade tumor (Grade 3) 5-year survival compared with 2-year survival, although decreasing by $16 \%$, however, retains $45 \%$, which is about three percent better than the overall survival in the study.

Montero and Patel describe that for the patient with oral cancer and metastases in cervical lymph nodes, the survival chance is decreased by $50 \%$ compared to a patient with identical oral tumor, but with no cervical lymph node metastases (Montero and Patel 2015). The data collected by the study confirm that the size and localization of the primary tumor are not decisive for the survival prognosis, but the presence of metastases in the cervical lymph nodes (Shah, Candela et al. 1990) is of decisive importance.

Scully et al. and Kumar et al. describe the important role of tumor localization in the patient's prognosis (Scully and Bagan 2009, Kumar, Nanavati 
et al. 2016). Tumor localization has an association with tumor propensity to metastase in cervical lymph nodes (Junior, Barboza et al. 2008). After a large number of authors of publications, tumors, localized in the tongue, have the greatest tendency to metastasize in cervical lymph nodes (Sessions, Spector et al. 2002, Noguti, De Moura et al. 2012, Lin, Jen et al. 2013, López-Cedrún and Andrés De Llano 2015, Le Campion, Ribeiro et al. 2017). When analysing the relationship of oral tumor localization to the lymph nodes in the neck, it was found that in both the study group and the control group, tumors localized in the tongue were prone to a high level of metastasization. This was $35 \%$ higher in the control group and reached $89 \%$.

To evaluate the effect of tumor excision lines on the results of surgical treatment and their association with survival, patients with clean excision lines and patients with tumor cells on excision lines were assessed. The importance of clean margins is no longer questioned (Franceschi, Gupta et al. 1993, Sessions, Spector et al. 2002, Luryi, Chen et al. 2014, Montero and Patel 2015, Chen, Lai et al. 2016, Stathopoulos and Smith 2017). This is the cornerstone for a successful outcome of treatment in oncosurgery. Our study indicates that tumor excision lines play a decisive role in patient's survival. In patients whose excision lines were clean 5-year survival reached $43 \%$. However, in patients whose excision lines were positive (tumor cells were on excision lines), no one lived for even two years.

In the study group, 3/4 of patients were undergoing soft-tissue reconstruction, whereas the assembly of soft and bone reconstruction was performed in a quarter of patients. The ratio of reconstructions types is explained by efforts to construct the oral cavity in the optimal solution. From the 113 transplanted fasciocutaneous flaps, radial forearm flap was used in 69\% of cases. Although radial forearm flap is ideal for the reconstruction of oral soft tissue, the problem of donor site is underlined as the main disadvantage of this 
flap. In order to avoid this, most often split-thickness or full-thickness skin graft is used. Literature data witnesses that the skin graft does not heal up to 53\% and the tendons are exposed in 33\% of cases (Swanson, Boyd et al. 1990). In our study group, patients undergoing radial forearm flap transplantation had a donor site closure with a skin graft in all patients. Although the lysis and secondary healing of skin graft was observed in a number of patients, no patient was required to undergo surgical donor site treatment. This was achieved due to the correct selection of the flap projection site.

The literature describes a large variety of osteocutaneous flap use. Vascularized rib, scapula, or illiac crest can be used when a major reconstruction of bone defects is required, but the most popular and most widely used flap is the free fibula flap. The fibula bone vascularization through periostium and available skin perforator allows to reconstruct soft and bone tissue defects in the mouth. The free fibula has become a "gold standard" worldwide (Lopez-Arcas, Arias et al. 2010).

In our study group, 31 osteocutaneous flaps were transplanted. In $98 \%$ of cases the free fibula was used, and only in $4 \%$ of cases other osteocutaneous flaps were applied. In one case, a scapula osteocutaneous flap was used and in one case crista iliaca osteocutaneous flap. The popularity of the free fibula comes from the constant anatomy with a thin skin island that is ideal for reconstruction of soft tissue defects in the oral cavity. The scapula flap is suitable for maxillary reconstruction because its flat form, which resembles the shape of the hard palate. Unfortunately, the blade bone is thin in virtually all of the area; it does not provide sufficient bone to ensure a later dental implantation. The second disadvantage of the flap is that the scapula flap skin part is, basically, a parascapular or a scapular flap, often with a thick layer of subcutaneous fat tissue. In order to ensure normal oral form and function, it is necessary to make the flap debulking. 
Grohmann et al. compared a free fibula, crista iliaca flap and a scapular flap. The author carried out a load test on the cadavers, who had reconstruction of the lower jaw with the above-mentioned flaps. The study confirmed that the lower jaw after reconstruction with free fibula presented the best result in the load test (Grohmann, Raith et al. 2015).

The estimated flap success rate varies with the literature data. This may reach up to $100 \%$ in small study groups (Sugiura, Sarukawa et al. 2018), however, in the large study groups, it ranges from $90 \%$ to $93 \%$ (Lopez-Arcas, Arias et al. 2010, Gerressen, Pastaschek et al. 2013, Shroff, Nair et al. 2017, Liang, Yu et al. 2018) with a higher tendency of survival directly for fasciocutaneous flaps. This is due to a relatively simpler operation and shorter operation time. An analysis of flap success rate in our study group showed that the total flap success rate of all transplanted flaps was $98.6 \%$, which is higher when compared to literature. The data in our study lead to the conclusion that the flap success rate determine the surgeons' skills and neccessisity to performe this type of surgery as a routine procedure with the sufficient patients flow.

In an analysis of post-operative complications in the study group, mortality reached $2.8 \%$. Comparing post-operative mortality as described in the literature, which may reach up to $20 \%$ (Mulvey, Brant et al. 2017), in our study group postoperative mortality did not exceed the lethality described in the literature. In analyzing the causes of death in the study group we found that $50 \%$ of deaths were caused by acute pulmonary thromboembolism. Compared to literature data, postoperative pulmonary complications can reach up to $18.8 \%$, but mortality is up to $6 \%$ (Loeffelbein, Julinek et al. 2016). In our study, the incidence of pulmonary thromboembolism and associated lethality is lower than the death rate from this cause described. Investigating the relatively small complications we found that they were in $11.9 \%$ of patients. The literature data indicates that the bleeding can reach up to 6\% of cases (Tsai, Chang et al. 2012, 
Pollei, Hinni et al. 2013), while fistulae that are a consequence for secondary wound healing can reach up to $10 \%$ (Lodders, Schulten et al. 2016, Zhou, Zhang et al. 2017). In our study group, the proportion of bleeding in 142 patients was higher $(9.8 \%)$ than described in the literature. In contrast, secondary healing in the postoperative period was observed in $2.1 \%$ cases of the 142 patients, a better score compared to the literature described. A statistically significant correlation ( $\mathrm{p}=0.03$ ) was observed in the study group data between the type of reconstruction and the complications. For patients with complex oral reconstruction, prospects that there will be complications are 2.50 times often compared to patients undergoing soft tissue reconstruction (95\% CI; 1.03-6.04).

Although the treatment methods of oral cancer have significantly developed, the survival of patients in advanced stages still has not substantially changed. Therefore, the assessment of quality of life is an increasingly important in the evaluation of treatment results. Understanding the influence of these factors on the treatment process and the patient, it would be preferable to develop a treatment plan to minimise the impact of treatment on the patient's quality of life (Murphy, Ridner et al. 2007).

In the literature, there are many QOL investigations about the patients with oral cancer, but they are mainly based on the studies analysing the QOL without detailed dividing patients in stages. There are relatively few studies analysing the QOL in patients with advanced oral cancer. Advanced-stage oral cancer is associated with a significant functional deterioration, perhaps associated with a tumor or treatment that has been used. The published data show that extensive tumor excision and the need for oral reconstruction are associated with a poor QOL, particularly emphasizing on the speech and swallowing function (Klozar, Lischkeova et al. 2001, Buchmann, Conlee et al. 2013, Milet, Mallet et al. 2010, Gobbo, Bullo et al. 2016). Of course, the findings may differ 
in similar patient groups, even within the same region or medical institution. This is due to the physician's experience and surgical technique.

Summarizing data, it is visible that the overall QOL has improved dramatically, patients estimate their overall health status as good. In B and C domains characterising the QOL after treatment, $75 \%$ of patients their healthrelated quality of life characterized as excellent or very good.

When analysing the disease-related domains, the data is different. Improvement is seen in the domains of pain, activity, mood and anxiety. No changes are observed in the shoulder and saliva domains, but the deterioration is observed in appearance, recreation, swallowing, speech, taste and chewing domains. Matsui et al. concluded that the ideal method of reconstruction is that which provides the least impact on the functionality (Matsui, Ohno et al. 2007). This is especially true for patients for whom a significant impact on the speech function was already expected before surgery. It was found that the speech was less affected in patients undergoing primary wound closure compared with patients for whom any type of flaps was used. Besides, there is still a discussion about the usefulness of the tongue reconstruction with a microvascular flap. Chen et al. expressed doubt in his publication about the need for the reconstruction of the tongue (Chen, Zhang et al. 2002). This was questioned by Hsiao et al. In their study, implicating that in the tongue reconstruction, although their speech function is inadequate, patients have a significant improvement in the swallowing function (Hsiao, Leu et al. 2003). Biglioli achieved good results in the use of inerved microvascular flaps, indicating that patients proceeded in evaluating both the swallowing and the speech function, thus improving the QOL standings (Biglioli, Liviero et al. 2006).

When assessing the percentage of the best possible answers, a significant improvement is evident in the pain domain while a moderate improvement is seen in the mood domain. No changes are in saliva and shoulder domains. If the 
saliva domain usually indicates the effect of radiotherapy on the quality of life, then the shoulder domain is associated with the cervical lymphadenectomy. Rathod et al. noted that the effect of cervical dissection on the QOL is reflected by reducing the number of points in the shoulder, appearance, recreation and activity domains (Rathod, Livergant et al. 2015). The percentage of best answers is slightly reduced in activity and anxiety domains, but moderately reduced in appearance, recreation, swallowing, and speech domains. A substantial percentage of the best possible answers are reduced in taste and chewing domains. The results of our study confirm the literature data and also indicate that the greatest deterioration is seen in chewing and taste domains. This is due to tooth loss and partial or total resection of the tongue during the surgery.

Interestingly, that in domains, in which a significant improvement or deterioration was observed, this was already noticed at the 3-month control point and at the 12-month control point there was only a minor correction. Conversely, in domains that remained stable during the study, a mild deterioration was observed at the 3-month control point. Rogers et al. observed the main prognostic factors that accumulate and influence the outcome of the QOL. They are tumor size, clinical functional status and type of surgery. He observed that the QOL tends to deteriorate after surgery for up to 6 months, followed by a moderate improvement to one year (Rogers, Lowe et al. 2002). The author acknowledged the importance of assessing the starting health status of the patient, as often the patient already had a functional deficiency before the treatment was started. It needs also to understand that return to the "exit point" does not mean a good QOL. Many studies have already demonstrated a changed QOL before initiation of therapy, which is associated with the newly diagnosed disease and patient's psychoemotional state.

By asking patients to mention the three most important problems before surgery, patients noted chewing, anxiety and pain, however 3 months and 
12 months after surgery the most important problems were chewing, speech and swallowing. As it can be seen, chewing is the most important QOL-reducing domain.

Patients' sex also plays an important role in the QOL prognosis. Patients with oral cancer often experience distress syndrome. It is more likely to develop directly in men, and its reduction in men is more uncommon than in women (Frampton 2001, Buchmann and Conlee et al. 2013). The impact of age on the QOL is controversial. Studies in the literature show lower tolerance and effect on quality of life in the elderly patient's group (Milet, Mallet et al. 2010). There are publications that conclude that the age of the patient does not affect the outcome of the QOL (Gobbo, Bullo et al. 2016). Our study indicates that the patient's age does not significantly affect the patient's QOL. The results suggest a tendency that comorbidities and the gender of the patient have a greater tendency to influence the QOL. De Araújo $J r$ et al. stated that the decisive worsening factor of the QOL is tumor localization. According to the author, the tongue, the soft palate and the base of the mouth have the worst prognosis for a squamous cell cancer of the oral cavity (Junior, Barboza et al. 2008). Comparing the three most important problems that patients are facing and that have a significant impact on the QOL, it is concluded that the patients in our study had very similar problems as described in the literature. 


\section{CONCLUSIONS}

1. Comparing 2-year survival in patients with advanced stage oral cancer that were undergoing surgical treatment of cancer, with patients who had radiotherapy as the primary treatment, the 2-year survival in the operated patients was $30 \%$ more often.

2. On the other hand, 5-year survival data show that radiotherapy does not provide 5-year survival for patients with oral cancer at advanced stage, in contradiction to surgical treatment providing 5-year survival in $42 \%$ of cases.

3. The most significant factors that have a statistically significant impact on patient survival are the resection lines status and the cervical lymph nodes involvement.

4. There is a conection between the type of oral reconstruction and the frequency of post-operative complications. In patients performing complex oral reconstruction, the possibility of developing complications is 2.5 times often than at the simple reconstruction of the oral cavity.

5. Significant improvement in the overall quality of life has been observed in advanced stage oral cancer patients after surgical treatment, however the disease-related quality of life is undetermined and exhibits a negative tendency. 


\section{PUBLICATIONS AND REPORTS ON THE STUDY THEME}

\section{Publications on the study theme}

Pastars, K., Zarins, J., Tars, J., Ivanova, A., Skagers, A. 2018. Microsurgical reconstruction of oral defects with free flaps for patients with oral cancer: an 8 year experience with 153 consecutive cases. Stomatologija, Baltic Dental and Maxillofacial Journal, 20, 39-42.

Pastars, K., Zarins, J., Tars, J., Ivanova, A., Skagers, A. 2018. Oral reconstruction with free lateral arm flap analysis of complication and donor site morbidity for patients with advanced stage oral cancer. Proceedings of Latvian Academy of Sciences. Section B, Vol. 72 (2018), No. 5 (716), 20-30.

Pastars, K., Tars, J., Ivanova, A., Zarins, J., Sivins, A., Skagers, A. 2015. Reconstruction of esophagus with free jejunal graft. Acta Chirurgica Latviensis No. 15/2, 21-24.

Pastars, K. Реконструкция дефекта пищевода с использованием кишечного трансплантата на сосудистой ножке. 2015. Orenburg Medical Journal No. 2.

\section{Reports in international conferences and congresses:}

Pastars, K., Keirans, A., Pilaps, Z., Kazanceva, A., Tars, J. Lower face reconstruction with double skin paddle free fibula. Case report. 2010. The $4^{\text {th }}$ World Congress of International Federation of Head and Neck Oncologic Societies, Seoul, South Korea.

Kazanceva, A., Tars, J., Kornevs, E., Sokolovs, J., Pastars, K., Groma, V. 2010. Clinical and Pathomorphological Results of 30 Patients with Head and Neck Reconstructions Using Microvascular Flaps and Bone Graft. Eur Arch Otorhinolaryngol.

Kazanceva, A., Tars, J., Kornevs, E., Lauskis, G., Pastars, K., Keirans, A., Groma, V. Clinical and pathomorphological results of 50 patients with head and neck 
reconstructions using microvascular flaps and bone grafts. 2010. Proc. $7^{\text {th }}$ Congr. Baltic Association Maxillofacial and Plastic Surgery, 44-45.

Kazanceva, A., Tars, J., Pastars, K., Groma, V., Kornevs, E., Keirans, A. 2010. Clinical and Pathomorphological Results of 40 Patients with Head and Neck Reconstructions Using Microvascular Flaps and Bone Grafts. Abstracts of the $4^{\text {th }}$ World Congress of International Federation of Head and Neck Oncologic Societies, 113.

Pastars, K., Keirans, A., Tars, J., Kazanceva, A. 2010. Head and neck soft tissue defect reconstruction with free flaps after tumor extirpation. $7^{\text {th }}$ Congress of Baltic Association for Maxillofacial and Plastic Surgery.

Pastars, K., Keirans, A., Tars, J., Kazanceva, A., Kornevs, A., Lauskis, G. 2010. Reconstruction of mandible defects with vascularised and nonvascularized bone grafts. $7^{\text {th }}$ Congress of Baltic Association for Maxillofacial and Plastic Surgery.

Pastars, K., Tars, J., Zarins, J., Ivanova, A., Keirans, A., Paulina, B., Pilaps Z. 2014. Outcome study of 87 patients with late stage oral cancers. $12^{\text {th }}$ Joint Symposium Riga-Rostok Head and Neck oncology: Treatment and reconstruction Options.

Pastars, K., Tars, J., Zarins, J., Ivanova, A., Keirans, A., Paulina, B., Pilaps Z. 2014. Reconstruction of esophagus with vascularised segment of intestine; late results (3 years follow up). 12 $2^{\text {th }}$ Joint Symposium Riga-Rostok Head and Neck oncology: Treatment and reconstruction Options.

Pastars, K. 2011. Reconstructive and aesthetic surgery of the head and neck. Joint meeting of Latvian association of plastic surgeons and Latvian association of oral and maxillofacial surgeons.

Keirans, A., Pastars, K., Zarins J., Pilaps, Z., Tars, J., Ivanova, A., Paulina, B. 2014. Radial forearm flap versus lateral arm flap for oral cavity reconstruction. $12^{\text {th }}$ Joint Symposium Riga-Rostok Head and Neck oncology: Treatment and reconstruction Options.

Zarins, J., Pastars, K., Tārs, J., Keirans, A., Ivanova, A., Paulina, B., Pilaps, Z. 2014. Assessment of quality of life after late stage oral cavity cancer reconstruction with free flaps. $12^{\text {th }}$ Joint Symposium Riga-Rostok Head and Neck oncology: Treatment and reconstruction Options. 
Bigestans, A., Salms, G., Skagers, A., Pastars, K., Kapickis, M. 2014. Case report: Treatment of fibrous dysplasia of the mandibule. $12^{\text {th }}$ Joint Symposium Riga-Rostok Head and Neck oncology: Treatment and reconstruction Options.

Kornevs, E., Tars, J. Lauskis, G., Kazanceva, A., Pastars, K., Paulina, B., Krastina A. 2014. Metastatic tumours of the parotid gland: Review of 20 years. $12^{\text {th }}$ Joint Symposium Riga-Rostok Head and Neck oncology: Treatment and reconstruction Options.

Pastars, K., Tars, J., Ivanova, A., Zarins, J., Keirans, A., Sivins, A., Januskevics, V. 2013. Esophageal reconstruction with vascularised intestine. $8^{\text {th }}$ congress of Baltic association for maxillofacial and plastic surgery.

Zarins, J., Pastars, K., Keirans, A., Tars, J., Ivanova A. 2013. Outcomne study of 87 patients with late stage oral cavity cancers: reconstruction, recurrence, survival rate and quality of life. $8^{\text {th }}$ congress of Baltic association for maxillofacial and plastic surgery.

Ivanova, A., Groma, V., Tars, J., Pastars, K., Kornevs, E., Liepa Z. 2011. Management of advanced SCC of the head and neck. $5^{\text {th }}$ Baltic Otorhinolaryngology Congress.

Ivanova, A., Groma, V., Tars, J., Pastars, K., Kornevs, E., Nora-Krukla, Z., Murovska, M. 2011. Epstein-Barr virus, Human herpes virus 6 and human herpes virus 7 association with oral squamous cell carcinoma and nasopharyngeal carcinoma. $5^{\text {th }}$ Baltic Otorhinolaryngplogy Congress.

Kazanceva, A., Groma, V., Kornevs, E., Tars, J., Pastars, K., Keirans, A. 2010. Clinical results of 50 patients with head and neck reconstructions using microvascular flaps and bone grafts. $7^{\text {th }}$ Congress of Baltic Association for Maxillofacial and Plastic Surgery.

Kazanceva, A., Tars, J., Groma, V., Pastars, K., Keirans, A., Kornevs, E. 2009. Reconstructive Surgery in the Head and Neck Oncology. Pirmais Baltijas valstu rekonstruktīvās, rokas un estētiskās ķirurgijas iepazī̌̌anās kongress.

Pastars K., Zarins J., Tars J. Complications of free lateral arm flap transfers: experience with 50 consecutive cases. Asian Pacific Federation of Societies for Surgery of the Hand 2017 (Indonesia). 
Pastars K. 2017. Rekonstruktīva mikroķirurǵija ielaistu mutes vēžu ārstēšanā. $8^{\text {th }}$ Latvian Doctor Congress. 


\section{REFERENCES}

1. Biglioli, F., Liviero, F., Frigerio, A., Rezzonico, A. and Brusati, R. 2006. Function of the sensate free forearm flap after partial glossectomy. Journal of CranioMaxillofacial Surgery, 34(6), 332-339.

2. Bittar, R. F., Ferraro, H. P., Ribas, M. H.and Lehn, C. N. 2016. Predictive factors of occult neck metastasis in patients with oral squamous cell carcinoma. Brazilian Journal of Otorhinolaryngology, 82(5), 543-547.

3. Brouha, X. D. R., Tromp, D. M., Hordijk, G. J., Winnubst, J. A. M.and de Leeuw, J. R. J. 2005. Oral and pharyngeal cancer: Analysis of patient delay at different tumor stages. Head and Neck-Journal for the Sciences and Specialties of the Head and Neck, 27(11), 939-945.

4. Buchmann, L., Conlee, J., Hunt, J., Agarwal, J. and White, S. 2013. Psychosocial Distress is Prevalent in Head and Neck Cancer Patients. Laryngoscope, 123(6), 14241429.

5. Chen, C. J., Zhang, Z. Y., Gao, S. P., Jiang, X. Q. and Zhang, Z. H. 2002. Speech after partial glossectomy: A comparison between reconstruction and nonreconstruction patients. Journal of Oral and Maxillofacial Surgery, 60(4), 404-407.

6. Chen, W. C., Lai, C. H., Fang, C. C., Yang, Y. H., Chen, P. C., Lee, C. P. and Chen, M. F. 2016. Identification of High-Risk Subgroups of Patients With Oral Cavity Cancer in Need of Postoperative Adjuvant Radiotherapy or Chemo-Radiotherapy. Medicine, 95(22).

7. Cheraghlou, S., Kuo, P., Mehra, S., Yarbrough, W. G. and Judson, B. L. 2018. Untreated oral cavity cancer: Long-term survival and factors associated with treatment refusal. Laryngoscope, 128(3), 664-669.

8. Fakih, A. R., Rao, R. S., Borges, A. M. and Patel, A. R. 1989. Elective versus therapeutic neck dissection in early carcinoma of the oral tongue. The American Journal of Surgery, 158(4), 309-313.

9. Frampton, M. 2001. Psychological distress in patients with head and neck cancer: review. British Journal of Oral \& Maxillofacial Surgery, 39(1), 67-70.

10. Franceschi, D., Gupta, R., Spiro, R. H. and Shah, J. P. 1993. Improved survival in the treatment of squamous carcinoma of the oral tongue. American Journal of Surgery, 166(4), 360-365.

11. Gerressen, M., Pastaschek, C. I., Riediger, D., Hilgers, R. D., Holzle, F., Noroozi, N. and Ghassemi, A. 2013. Microsurgical Free Flap Reconstructions of Head and Neck Region in 406 Cases: A 13-Year Experience. Journal of Oral and Maxillofacial Surgery, 71(3), 628-635.

12. Gobbo, M., Bullo, F., Perinetti, G., Gatto, A., Ottaviani, G., Biasotto, M. and Tirelli, G. 2016. Diagnostic and therapeutic features associated with modification of quality- 
of-life's outcomes between one and six months after major surgery for head and neck cancer. Brazilian Journal of Otorhinolaryngology, 82(5), 548-557.

13. Gorsky, M. and Dayan, D. 1995. Referral delay in diagnosis of oro/oropharyngeal cancer in Israel. Oral Oncology-European Journal of Cancer Part B, 31B(3), 166168.

14. Grohmann, I., Raith, S., Muecke, T., Stimmer, H., Rohleder, N., Kesting, M. R., Holzle, F. and Steiner, T. 2015. Biomechanical loading test on reconstructed mandibles with fibular, iliac crest or scapula graft: a comparative study. British Journal of Oral \& Maxillofacial Surgery, 53(8), 741-747.

15. Hsiao, H. T., Leu, Y. S. and Lin, C. C. 2003. Tongue reconstruction with free radial forearm flap after hemiglossectomy: A functional assessment. Journal of Reconstructive Microsurgery, 19(3), 137-142.

16. Huang, S. H. and O'Sullivan, B. 2013. Oral cancer: Current role of radiotherapy and chemotherapy. Medicina Oral Patologia Oral Y Cirugia Bucal, 18(2), E233-E240.

17. Huang, S. H. and O'Sullivan, B. 2017. Overview of the 8th Edition TNM Classification for Head and Neck Cancer. Current Treatment Options in Oncology, 18(7).

18. Jemal, A. 2011. Global Cancer Statistics (Vol 61, 69). Ca-a Cancer Journal for Clinicians, 61(2), 134-134.

19. Junior, R., Barboza, C. A. G., Clebis, N. K., de Moura, S. A. and Costa, A. D. L. 2008. Prognostic significance of the anatomical location and TNM clinical classification in oral squamous cell carcinoma. Medicina Oral Patologia Oral Y Cirugia Bucal, 13(6), E344-E347.

20. Klozar, J., Lischkeova B. and Betka, J. 2001. Subjective functional results 1 year after surgery and postoperative radiation for oropharyngeal carcinoma. European Archives of Oto-Rhino-Laryngology, 258(10), 546-551.

21. Kumar, M., Nanavati, R., Modi, T. G. and Dobariya, C. 2016. Oral cancer: Etiology and risk factors: A review. Journal of Cancer Research and Therapeutics, 12(2), 458463.

22. Kumar, V. V., Kumar, U., Pillai, V., Ponnusamy, V., Al-Nawas, B. and Kuriakose, M. A. 2017. Implant Stability and Bone Characteristics in Free Fibula Flaps Used for Jaw Reconstruction: A Prospective Cohort Study. International Journal of Oral \& Maxillofacial Implants, 32(5), 1145-1152.

23. Lambert, R., Sauvaget, C., Cancela, M. D. and Sankaranarayanan, R. 2011. Epidemiology of cancer from the oral cavity and oropharynx. European Journal of Gastroenterology \& Hepatology, 23(8), 633-641.

24. Le Campion, A. C. O. V., Ribeiro, C. M. B., Luiz, R. R., da Silva Júnior, F. F., Barros, H. C. S., Dos Santos, K. C. B., Ferreira, S. J., Gonçalves, L. S. and Ferreira, S. M. S. 2017. Low Survival Rates of Oral and Oropharyngeal Squamous Cell Carcinoma. Int J Dent, 2017, 5815493. 
25. Leon, X., Martinez, V., Lopez, M., Garcia, J., del Prado Venegas, M., Esteller, E. and Quer, M. 2012. Second, third, and fourth head and neck tumors. A progressive decrease in survival. Head and Neck-Journal for the Sciences and Specialties of the Head and Neck, 34(12), 1716-1719.

26. Liang, J. W., Yu, T., Wang, X., Zhao, Y. J., Fang, F. Q., Zeng, W. and Li, Z. D. 2018. Free tissue flaps in head and neck reconstruction: clinical application and analysis of 93 patients of a single institution. Brazilian Journal of Otorhinolaryngology, 84(4), 416-425.

27. Lin, C. S., Jen, Y. M., Kao, W. Y., Ho, C. L., Dai, M. S., Shih, C. L., Cheng, J. C., Chang, P. Y., Huang, W. Y. and Su, Y. F. 2013. Improved outcomes in buccal squamous cell carcinoma. Head Neck, 35(1), 65-71.

28. Lodders, J. N., Schulten, E., de Visscher, J., Forouzanfar, T. and Karagozoglu, K. H. 2016. Complications and Risk after Mandibular Reconstruction with Fibular Free Flaps in Patients with Oral Squamous Cell Carcinoma: A Retrospective Cohort Study. Journal of Reconstructive Microsurgery 32(6): 455-463.

29. Loeffelbein, D. J., Julinek, A., Wolff, K. D., Kochs, E., Haller, B. and Haseneder, R. 2016. Perioperative risk factors for postoperative pulmonary complications after major oral and maxillofacial surgery with microvascular reconstruction: A retrospective analysis of 648 cases. Journal of Cranio-Maxillofacial Surgery, 44(8), 952-957.

30. Lonie, S., Herle, P., Paddle, A., Pradhan, N., Birch, T. and Shayan, R. 2016. Mandibular reconstruction: meta-analysis of iliac-versus fibula-free flaps. Anz Journal of Surgery, 86(5), 337-342.

31. Lopez-Arcas, J. M., Arias, J., Del Castillo, J. L., Burgueno, M., Navarro, I., Moran, M. J., Chamorro, M. and Martorell, V. 2010. The Fibula Osteomyocutaneous Flap for Mandible Reconstruction: A 15-Year Experience. Journal of Oral and Maxillofacial Surgery, 68(10), 2377-2384.

32. López-Cedrún, J. L. and Andrés de Llano, J. 2015. A 22 years survival and prognostic factors analysis in a homogeneous series of 64 patients with advanced cancer of the tongue and the floor of the mouth. J Craniomaxillofac Surg, 43(3), 376-381.

33. Luryi, A. L., Chen, M. M., Mehra, S., Roman, S. A., Sosa, J. A. and Judson, B. L. 2014. Positive Surgical Margins in Early Stage Oral Cavity Cancer: An Analysis of 20,602 Cases. Otolaryngology-Head and Neck Surgery, 151(6), 984-990.

34. Maldonado, A. A. and Langerman, A. 2017. Fibula osteofascial flap with proximal skin paddle for intraoral reconstruction. Microsurgery, 37(4), 276-281.

35. Matsui, Y., Ohno, K., Yamashita, Y. and Takahashi, K. (2007). Factors influencing postoperative speech function of tongue cancer patients following reconstruction with fasciocutaneous/myocutaneous flaps - a multicenter study. International Journal of Oral and Maxillofacial Surgery, 36(7), 601-609. 
36. Milet, P. R., Mallet, Y., El Bedoui, S., Penel, N., Servent, V. and Lefebvre, J. L. 2010. Head and neck cancer surgery in the elderly - Does age influence the postoperative course? Oral Oncology, 46(2), 92-95.

37. Montero, P. H. and Patel, S. G. 2015. Cancer of the oral cavity. Surg Oncol Clin N Am, 24(3), 491-508.

38. Morelatto, R. A., Herrera, M. C., Fernandez, E. N., Corball, A. G. and Lopez De Blanc, S. A. 2007. Diagnostic delay of oral squamous cell carcinoma in two diagnosis centers in Cordoba Argentina. Journal of Oral Pathology \& Medicine, 36(7), 405408.

39. Mulvey, C. L., Brant, J. A., Bur, A. M., Chen, J. B., Fischer, J. P., Cannady, S. B. and Newman, J. G. 2017. Complications Associated with Mortality after Head and Neck Surgery: An Analysis of the NSQIP Database. Otolaryngology-Head and Neck Surgery, 156(3), 504-510.

40. Murphy, B. A., Ridner, S., Wells, N. and Dietrich, M. 2007. Quality of life research in head and neck cancer: A review of the current state of the science. Critical Reviews in Oncology Hematology, 62(3), 251-267.

41. Noguti, J., De Moura, C. F. G., De Jesus, G. P. P., Da Silva, V. H. P., Hossaka, T. A., Oshima, C. T. F. and Ribeiro, D. A. 2012. Metastasis from Oral Cancer: An Overview. Cancer Genomics \& Proteomics, 9(5), 329-335.

42. Onizawa, K., Nishihara, K., Yamagata, K., Yusa, H., Yanagawa, T. and Yoshida, H. 2003. Factors associated with diagnostic delay of oral squamous cell carcinoma. Oral Oncology, 39(8), 781-788.

43. Patel, U. A., Hartig, G. K., Hanasono, M. M., Lin, D. T. and Richmon, J. D. 2017. Locoregional Flaps for Oral Cavity Reconstruction: A Review of Modern Options. Otolaryngology - Head and Neck Surgery (United States), 157(2), 201-209.

44. Pollei, T. R., Hinni, M. L., Moore, E. J., Hayden, R. E., Olsen, K. D., Casler, J. D. and Walter, L. C. 2013. Analysis of Postoperative Bleeding and Risk Factors in Transoral Surgery of the Oropharynx. Jama Otolaryngology-Head \& Neck Surgery, 139(11), 1212-1218.

45. Punhani, N., Dongarwar, G. R., Mahajan, H., Daniel, M. J., Chalapathi, K. V. and Nayyar, A. S. 2017. Tumor Size and Its Relation to Cervical Lymph Node Metastasis and Its Significance as a Prognostic Indicator for Oral Squamous Cell Carcinomas. Clinical Cancer Investigation Journal, 6(3), 153-166.

46. Rathod, S., Livergant, J., Klein, J., Witterick, I. and Ringash, J. (2015). A systematic review of quality of life in head and neck cancer treated with surgery with or without adjuvant treatment. Oral Oncol, 51(10), 888-900.

47. Rogers, S. N., Fisher, S. E. and J. A. Woolgar. 1999. A review of quality of life assessment in oral cancer. International Journal of Oral and Maxillofacial Surgery, 28(2), 99-117. 
48. Rogers, S. N., Lowe, D., Brown, J. S. and Vaughan, E. D. 1999. The University of Washington head and neck cancer measure as a predictor of outcome following primary surgery for oral cancer. Head and Neck-Journal for the Sciences and Specialties of the Head and Neck, 21(5), 394-401.

49. Rogers, S. N., Lowe, D., Fisher, S. E., Brown, J. S. and Vaughan, E. D. 2002. Healthrelated quality of life and clinical function after primary surgery for oral cancer. British Journal of Oral \& Maxillofacial Surgery, 40(1), 11-18.

50. Rogers, S. N., Miller, R. D., Ali, K., Minhas, A. B., Williams, H. F. and Lowe D. 2006. Patients' perceived health status following primary surgery for oral and oropharyngeal cancer. International Journal of Oral and Maxillofacial Surgery, 35(10), 913-919.

51. Rubright, W. C., Hoffman, H. T., Lynch, C. F., Kohout, F. J., Robinson, R. A., Graham, S., Funk G. and McCulloch T. 1996. Risk factors for advanced-stage oral cavity cancer. Archives of Otolaryngology-Head \& Neck Surgery, 122(6), 621-626.

52. Schneider, I. J., Flores, M. E., Nickel, D. A., Martins, L. G. and Traebert J. 2014. Survival rates of patients with cancer of the lip, mouth and pharynx: a cohort study of 10 years. Rev Bras Epidemiol, 17(3), 680-691.

53. Scully, C. and Bagan, J. 2009. Oral squamous cell carcinoma overview. Oral Oncology, 45(4), 301-308.

54. Sessions, D. G., Spector, G. J., Lenox, J., Haughey, B., Chao, C. and Marks, J. 2002. Analysis of treatment results for oral tongue cancer. Laryngoscope, 112(4), 616-625.

55. Sessions, D. G., Spector, G. J., Lenox, J., Parriott, S., Haughey, B., Chao, C., Marks, J. and Perez, C. 2000. Analysis of treatment results for floor-of-mouth cancer. Laryngoscope, 110(10), 1764-1772.

56. Shah, J. P., Candela, F. C. and Poddar, A. K. 1990. The patterns of cervical lymph node metastases from squamous carcinoma of the oral cavity. Cancer, 66(1), 109-113.

57. Shah, J. P. and Gil, Z. 2009. Current concepts in management of oral cancer - Surgery. Oral Oncology, 45(4-5), 394-401.

58. Shroff, S. S., Nair, S. C., Shah, A. and Kumar B. 2017. Versatility of Fibula Free Flap in Reconstruction of Facial Defects: A Center Study. Journal of Maxillofacial \& Oral Surgery, 16(1), 101-107.

59. Smee, R. I., Broadley, K., Bridger, G. P. and Williams, J. 2012. Floor of mouth carcinoma: Surgery still the dominant mode of treatment. Journal of Medical Imaging and Radiation Oncology, 56(3), 338-346.

60. Stathopoulos, P. and Smith, W. 2017. Analysis of Survival Rates Following Primary Surgery of 178 Consecutive Patients with Oral Cancer in a Large District General Hospital. Journal of Maxillofacial \& Oral Surgery, 16(2), 158-163. 
61. Sugiura, Y., Sarukawa, S., Hayasaka, J., Kamochi, H., Noguchi, T. and Mori Y. 2018. Mandibular reconstruction with free fibula flaps in the elderly: a retrospective evaluation. International Journal of Oral and Maxillofacial Surgery, 47(8), 983-989.

62. Swanson, E., Boyd, J. B. and Manktelow, R. T. 1990. The radial forearm flap: Reconstructive applications and donor-site defects in 35 consecutive patients. Plastic and Reconstructive Surgery, 85(2), 258-266.

63. Tangthongkum, M., Kirtsreesakul, V., Supanimitjaroenporn, P. and Leelasawatsuk, P. 2017. Treatment outcome of advance staged oral cavity cancer: concurrent chemoradiotherapy compared with primary surgery. Eur Arch Otorhinolaryngol, 274(6), 2567-2572.

64. Tsai, C. H., Chang, K. P., Hung, S. Y., Chen, W. F., Cheng, M. H. and Kao, H. K. 2012. Postoperative morbidity in head and neck cancer ablative surgery followed by microsurgical free tissue transfer in the elderly. Oral Oncology, 48(9), 811-816.

65. Weatherspoon, D. J., Chattopadhyay, A., Boroumand, S. and Garcia, I. 2015. Oral cavity and oropharyngeal cancer incidence trends and disparities in the United States: 2000-2010. Cancer Epidemiology, 39(4), 497-504.

66. Xu, Z. F., Bai, S., Zhang, Z. Q., Duan, W. Y., Wang, Z. Q. and Sun, C. F. 2017. A critical assessment of the fibula flap donor site. Head and Neck-Journal for the Sciences and Specialties of the Head and Neck, 39(2), 279-287.

67. Zhou, W., Zhang, W. B., Yu, Y., Wang, Y., Mao, C., Guo, C. B., Yu, G. Y. and Peng, X. 2017. Risk factors for free flap failure: a retrospective analysis of 881 free flaps for head and neck defect reconstruction. International Journal of Oral and Maxillofacial Surgery, 46(8), 941-945. 


\section{ACKNOWLEDGEMENTS}

I express my deep appreciation to my supervisor Professor Andrejs Skaǵers for his support, guidance, valuable recommendations and patience in the composing of the Thesis.

Many thanks to Docent Anna Ivanova for persistent insistence and encouragement to start and to carry out investigations with advanced stage oral cancer patients.

I would like to thank the head of Latvian Onocolgy Centre Head and Neck surgery department Juris Tārs for opportunity open new page in Latvian head and neck surgery chapter.

I express my gratitude to my colleagues of Microsurgery Centre of Latvia for unbelievable support in different ways during the study.

I thank Assistant Professor Renārs Erts for his help and advice performing statistical calculations.

Hearty thanks to Ilze Mutule, without her help and support it would be impossible to accomplish.

The biggest thanks to my beloved family for patience and understanding. 